\title{
Iron and aluminum association with microbially processed organic matter via meso-density aggregate formation across soils: organo-metallic glue hypothesis
}

\author{
Rota Wagai $^{1}$, Masako Kajiura ${ }^{1}$, and Maki Asano ${ }^{2}$ \\ ${ }^{1}$ National Agriculture and Food Research Organization, Institute for Agro-Environmental Sciences, \\ 3-1-3 Kan-nondai, Tsukuba, Ibaraki, 305-8604, Japan \\ ${ }^{2}$ Faculty of Life and Environmental Sciences, University of Tsukuba, \\ 1-1-1 Tennodai, Tsukuba, Ibaraki 305-8572, Japan
}

Correspondence: Rota Wagai (rota@affrc.go.jp)

Received: 16 May 2020 - Discussion started: 11 June 2020

Revised: 3 September 2020 - Accepted: 26 September 2020 - Published: 7 December 2020

\begin{abstract}
Global significance of iron (Fe) and aluminum ( $\mathrm{Al}$ ) for the storage of organic matter ( $\mathrm{OM})$ in soils and surface sediments is increasingly recognized. Yet specific metal phases involved or the mechanism behind metal-OM correlations frequently shown across soils remain unclear. We identified the allocation of major metal phases and OM to density fractions using 23 soil samples from five climate zones and five soil orders (Andisols, Spodosols, Inceptisols, Mollisols, Ultisols) from Asia and North America, including several subsurface horizons and both natural and managed soils. Each soil was separated into four to seven density fractions using sodium polytungstate with mechanical shaking, followed by the sequential extraction of each fraction with pyrophosphate (PP), acid oxalate (OX), and finally dithionite-citrate (DC) to estimate pedogenic metal phases of different solubility and crystallinity. The concentrations of $\mathrm{Fe}$ and $\mathrm{Al}$ (per fraction) extracted by each of the three reagents were generally higher in meso-density fractions $\left(1.8-2.4 \mathrm{~g} \mathrm{~cm}^{-3}\right)$ than in the lower- or higher-density fractions, showing a unique unimodal pattern along the particle density gradient for each soil. Across the studied soils, the maximum metal concentrations were always at the meso-density range within which PP-extractable metals peaked at $0.3-0.4 \mathrm{~g} \mathrm{~cm}^{-3}$ lower-density range relative to OX- and DC-extractable metals. Meso-density fractions, consisting largely of aggregated clusters based on SEM observation, accounted for on average $56 \%-70 \%$ of total extractable metals and OM present in these soils. The OM in meso-density fractions showed a 2-23 unit lower $\mathrm{C}: \mathrm{N}$ ratio than the lowest-density fraction of the respective soil and thus appeared microbially processed relative to the original plant material. The amounts of PP- and OX-extractable metals correlated positively with co-dissolved $\mathrm{C}$ across the soils and, to some extent, across the density fractions within each soil. These results led to a hypothesis which involves two distinct levels of organo-metal interaction: (1) the formation of OMrich, mixed metal phases with fixed OM : metal stoichiometry followed by (2) the development of meso-density microaggregates via "gluing" action of these organo-metallic phases by entraining other organic and mineral particles such as phyllosilicate clays. Given that OM is mainly located in meso-density fractions, a soil's capacity to protect OM may be controlled by the balance of three processes: (i) microbial processing of plant-derived $\mathrm{OM}$, (ii) dissolution of metals, and (iii) the synthesis of organo-metallic phases and their association with clays to form meso-density microaggregates. The current hypothesis may help to fill the gap between well-studied molecular-scale interaction (e.g., OM adsorption on mineral surface, coprecipitation) and larger-scale processes such as aggregation, $\mathrm{C}$ accrual, and pedogenesis.
\end{abstract}




\section{Introduction}

Organic matter $(\mathrm{OM})$ stored in soil plays a fundamental role in ecosystem functioning through the storage of carbon (C) and nutrients, improvement of aeration and water-holding capacity, and thus plant productivity and biogeochemical cycling. Changes in soil OM have a significant impact on future climate as soil represents the largest terrestrial $\mathrm{C}$ pool. The storage capacity and stability of soil OM are particularly important questions for our efforts to limit global warming (Smith, 2016). Soil OM stability is strongly controlled by its association with soil minerals via chemical interaction and physical aggregation (Lehmann and Kleber, 2015; Sollins et al., 1996). The mineral parameters often used to estimate soil's protective capacity are clay content $(<2 \mu \mathrm{m})$ or clay plus silt content $(<20 \mu \mathrm{m})$ of soils as they often correlate with soil OM contents, and these small-sized minerals tend to have a high surface area to adsorb OM (Six et al., 2002, and the references therein). Commonly used mathematical models to predict soil $\mathrm{C}$ changes use these parameters to slow down OM turnover and to increase its storage (Coleman and Jenkinson, 1996; Parton et al., 1987; Wieder et al., 2015).

On the other hand, the global significance of iron $(\mathrm{Fe})$ and aluminum (Al) phases for OM storage in soil and surface sediments has been increasingly recognized. Using 5500 pedons around the world, Rasmussen et al. (2018) showed stronger control of organic $\mathrm{C}$ storage in non-arid soils by oxalate-extractable metal content than by clay content. Important linkage among climate (especially water balance), dissolved organic $\mathrm{C}$ production, and its stabilization by these metal phases has been shown on a continental scale (Kramer and Chadwick, 2018). Surface marine sediments also store significant amounts of Fe-bound C (Lalonde et al., 2012). Iron and aluminum, the third and fourth most abundant elements on the earth crust, are in fact highly reactive with $\mathrm{OM}$ once released via chemical weathering. These pedogenic $\mathrm{Fe}$ and $\mathrm{Al}$ can be present in monomeric form by chelating with organic ligands or in polymeric form as polynuclear complexes and as secondary minerals. The latter includes $\mathrm{Fe}$ and $\mathrm{Al}$ oxides, hydroxides, and oxyhydroxides (collectively called metal oxides, hereafter) as well as short-range-order aluminosilicates (allophane, imogolite, and proto-imogolite) that have high sorptive capacity for OM due to their small size (down to several nanometers) and high surface reactivity via surface hydroxyl groups (Fuji et al., 2019; Kaiser and Guggenberger, 2003; Kleber et al., 2015). In addition, soluble complexes of $\mathrm{Fe}$ and $\mathrm{Al}$ with organic ligands can be precipitated especially in acidic, OM-rich environments such as volcanic and podzolic soils (Lundström et al., 2000; Percival et al., 2000; Takahashi and Dahlgren, 2016).

Incorporating such metal control into soil $\mathrm{C}$ models is still a challenge because the mechanisms by which pedogenic metals control OM storage and stabilization remain elusive. This is partly because current understanding relies largely on $\mathrm{OM}$-metal correlations where the metal concentration often co-varies with other soil properties. The reactive metal contents often positively correlate with other mineralogical parameters that are considered to contribute to OM storage such as clay content and soil-specific surface area (e.g., Kaiser and Guggenberger, 2003; Mayer and Xing, 2001). In longterm pedogenesis (240-4100 kyr) under a temperate or tropical moist climate regime, radiocarbon-based soil $\mathrm{C}$ age was positively correlated with extractable metal contents in two chronosequence studies (Masiello et al., 2004; Torn et al., 1997) but not in another study under wetter climate where only soil-specific surface area and halloysite content showed significant correlation (Lawrence et al., 2015). Short-rangeorder minerals and $\mathrm{Fe}$ oxides can also promote aggregation (Churchman and Tate, 1986; Oades and Waters, 1991; Shang and Tiessen, 1998), which indirectly enhances OM stability (Balesdent et al., 2000; Totsche et al., 2017) without necessarily showing proportionality to metal concentrations.

To untangle co-varying factors, Wagai and Mayer (2007) assessed $\mathrm{Fe}$ oxide contribution to $\mathrm{C}$ storage by quantifying the $\mathrm{C}$ released during the reductive $\mathrm{Fe}$ oxide dissolution with dithionite for soils covering eight soil orders. After correcting for the $\mathrm{OC}$ release due to salt and extractive $\mathrm{pH}$ effects, the study conservatively estimated that $2 \%-25 \%$ (up to $60 \%$ for a highly weathered, Fe-rich soil) of total soil $\mathrm{OM}$ was $\mathrm{Fe}$-bound and the $\mathrm{C}: \mathrm{Fe}$ ratio of the extracts suggested greater contribution of precipitated organo-metal complexes than simple adsorptive association in lower-pH soils. Subsequent dithionite-based studies confirmed that less than half (typically less than a quarter) of total OM was associated with $\mathrm{Fe}$ in a range of soils and sediments (Coward et al., 2018, 2017; Lalonde et al., 2012; Zhao et al., 2016). Wagai et al. (2013) further examined the potential contribution of other metal phases such as short-range-order minerals, organo-metal complexes, and their coprecipitates using other extractants and showed that, even as liberal estimates, $5 \%-60 \%$ of total OM in a range of acidic to near-neutral soils (higher percentages for volcanic soils and spodic horizons) could be explained by direct association with $\mathrm{Fe}$ and $\mathrm{Al}$ phases. The limited extractability of $\mathrm{OM}$ with these metal phases implied the potentially critical role of physical protection via ternary associations of OM, metals, and clay (Wagai and Mayer, 2007). More recent studies showed that a portion of soil $\mathrm{Fe}$ phases in soil can be protected from reductive dissolution (dithionite extraction) due presumably to physical protection within microaggregates or coprecipitation with short-range-order aluminosilicates (Coward et al., 2018; Suda and Makino, 2016; Filimonova et al., 2016), suggesting both the limitation of a single-extraction approach and the importance of aggregation-precipitation reactions. On the other hand, experimental studies revealed specific factors and underlying mechanisms behind OM-metal interaction via adsorption, complexation, and coprecipitation using pure metal phases under well-defined laboratory conditions (Chen et al., 2014; Mikutta et al., 2011; Nierop et al., 2002; Schneider et al., 2010; Tamrat et al., 2019; Kaiser, 2003). 
However, a large knowledge gap still remains between the laboratory studies and field-based studies (see a review by Kleber et al., 2015).

Critical to filling this gap is to identify factors controlling the distribution and localization of different pedogenic metal phases in soil systems because different modes of organo-metal association likely take place at specific local environments. At larger spatial scales, mobilization and accumulation of pedogenic metal phases and their interaction with $\mathrm{OM}$ over time and along soil profile depth have been well-recognized (e.g., Kramer et al., 2012; Lawrence et al., 2015). At micro- to nano-meter scales, on the other hand, advanced imaging techniques revealed co-localization of OM and pedogenic $\mathrm{Fe}$ and $\mathrm{Al}$ in natural soils (Asano et al., 2018; Garcia Arredondo et al., 2019; Inagaki et al., 2020; Wan et al., 2007), although up-scaling of such information remains a major challenge. At horizon or bulk soil scales, physical fractionation studies have indicated the presence - but not the spatial arrangement - of multiple OM pools of varying turnover rate and degree of mineral associations (Christensen, 2001; von Lützow et al., 2007).

Density provides a useful fractionation approach to assess the localization of pedogenic $\mathrm{Fe}$ and $\mathrm{Al}$ phases because many biogeochemical characteristics of soil particles are closely related to their density (Christensen, 2001; Sollins et al., 2009; Turchenek and Oades, 1979; von Lützow et al., 2007). The density of soil particles is primarily controlled by the relative amounts of the two major components, OM and mineral. The average density of OM present in soil is typically around $1.4 \mathrm{~g} \mathrm{~cm}^{-3}$ but can range between 1.1 and $1.9 \mathrm{~g} \mathrm{~cm}^{-3}$ across soils and sediments (Mayer et al., 2004). The minerals typically found in soils such as aluminosilicate clays have the density of $>2.4 \mathrm{~g} \mathrm{~cm}^{-3}$ including short-range-order allophane and imogolite (2.75 and $2.70 \mathrm{~g} \mathrm{~cm}^{-3}$, Wada, 2018) with minor exceptions such as phytoliths $\left(2.1-2.15 \mathrm{~g} \mathrm{~cm}^{-3}\right.$, Drees et al., 1989). Among metal oxides, Fe oxides have much higher densities $\left(3.8-5.3 \mathrm{~g} \mathrm{~cm}^{-3}\right.$, Cornell and Schwertmann, 2003) compared with Al hydroxides such as gibbsite $\left(2.4 \mathrm{~g} \mathrm{~cm}^{-3}\right.$, Anthony et al., 1997). Pedogenic metals can remain as distinct phases or they can associate with $\mathrm{OM}$ or other minerals. From the perspective of OM, both pedogenic metals and other minerals will be found in a highdensity fraction $\left(>2.4 \mathrm{~g} \mathrm{~cm}^{-3}\right)$ unless they associate with $\mathrm{OM}$. While $\mathrm{OM}$ binding lowers the density of $\mathrm{Fe}$ and $\mathrm{Al}$ phases in the laboratory (Kaiser and Guggenberger, 2007), its extent under various pedogenic environments is virtually unstudied.

We hypothesize that most pedogenic metals are found in $<2.4 \mathrm{~g} \mathrm{~cm}^{-3}$ density fractions regardless of soil type due to their high reactivity with OM. Because of the higher density and redox sensitivity, pedogenic Fe may concentrate in different density phases from pedogenic $\mathrm{Al}$ for any given soil, assuming that organo-Fe and organo- $\mathrm{Al}$ associations take place independently. Alternatively, if the metal dissolution and subsequent interaction with $\mathrm{OM}$ are regu- lated by the same environmental factors, their distribution along the particle density gradient would be similar. Furthermore, if submicron-sized, OM-rich metal phases act as binding agents as suggested for a volcanic soil based on STXM/NEXAFS and electron microscopy (Asano and Wagai, 2014; Asano et al., 2018), they may preferentially bind with other fine-sized minerals (e.g., clays) to form the ternary associations previously postulated (Wagai and Mayer, 2007). These ideas were tested by fractionating soil particles into four to seven density classes after a mild level of dispersion (mechanical shaking in solution) and by quantifying the amounts of $\mathrm{Fe}$ and $\mathrm{Al}$ phases by selective dissolution techniques that target different metal phases (pyrophosphate, acid oxalate, and dithionite-citrate extractions in sequence) using 23 soil samples from 11 sites spanning 5 climate zones and 5 soil orders (Andisols, Spodosols, Inceptisols, Mollisols, Ultisols) and including several subsurface horizons and both natural and managed (upland and paddy) soils.

Terminology: weathering products of Fe- and Al-bearing minerals during pedogenesis are collectively called "pedogenic Fe and Al phases" in this study. We use the term "complex" to refer to aqueous organo-metal complexes and their precipitates and avoid its use to describe broader associations such as organo-clay and organo-mineral complex. Various types of OM-metal association are discussed by grouping into three general mechanisms (adsorption, complexation, and aggregation) while recognizing that organo-metal complexes in soil are mainly coprecipitated with other metal phases and particles. The term "particle" is used in a broad sense to include aggregates as well as single organic or mineral particles.

\section{Methods}

\subsection{Soil sample source}

The soil samples selected for this study reflect our primary interest in the soils and soil horizons that hold high OM via its interaction with reactive mineral phases. A soil sample set consisted of four groups: allophanic Andisol (silandic), nonallophanic (aluandic) Andisol, spodic, and crystalline mineralogy $(n=23$, Table 1$)$ groups, including both natural and cultivated soils from six climate zones with a wide range of mean annual temperature $\left(5-24^{\circ} \mathrm{C}\right)$ and precipitation $(221-$ $2392 \mathrm{~mm} \mathrm{yr}^{-1}$ ).

Allophanic Andisol samples were collected in the Kanto plain and Kofu basin, Japan. Parent material is mainly rhyolitic and basaltic volcanic ash deposits. Dominant claysized minerals are short-range-order (SRO) minerals - more allophane-/imogolite-type minerals than hydrous iron oxides such as ferrihydrite. Minor amounts of gibbsite, kaolinite, chlorite, hydroxyl-interlayered vermiculite, mica, quartz, and feldspar are often found in these soils. Five of the samples were from a long-term field experiment for OM management (A-1 to A-5) and the data from these samples have been re- 


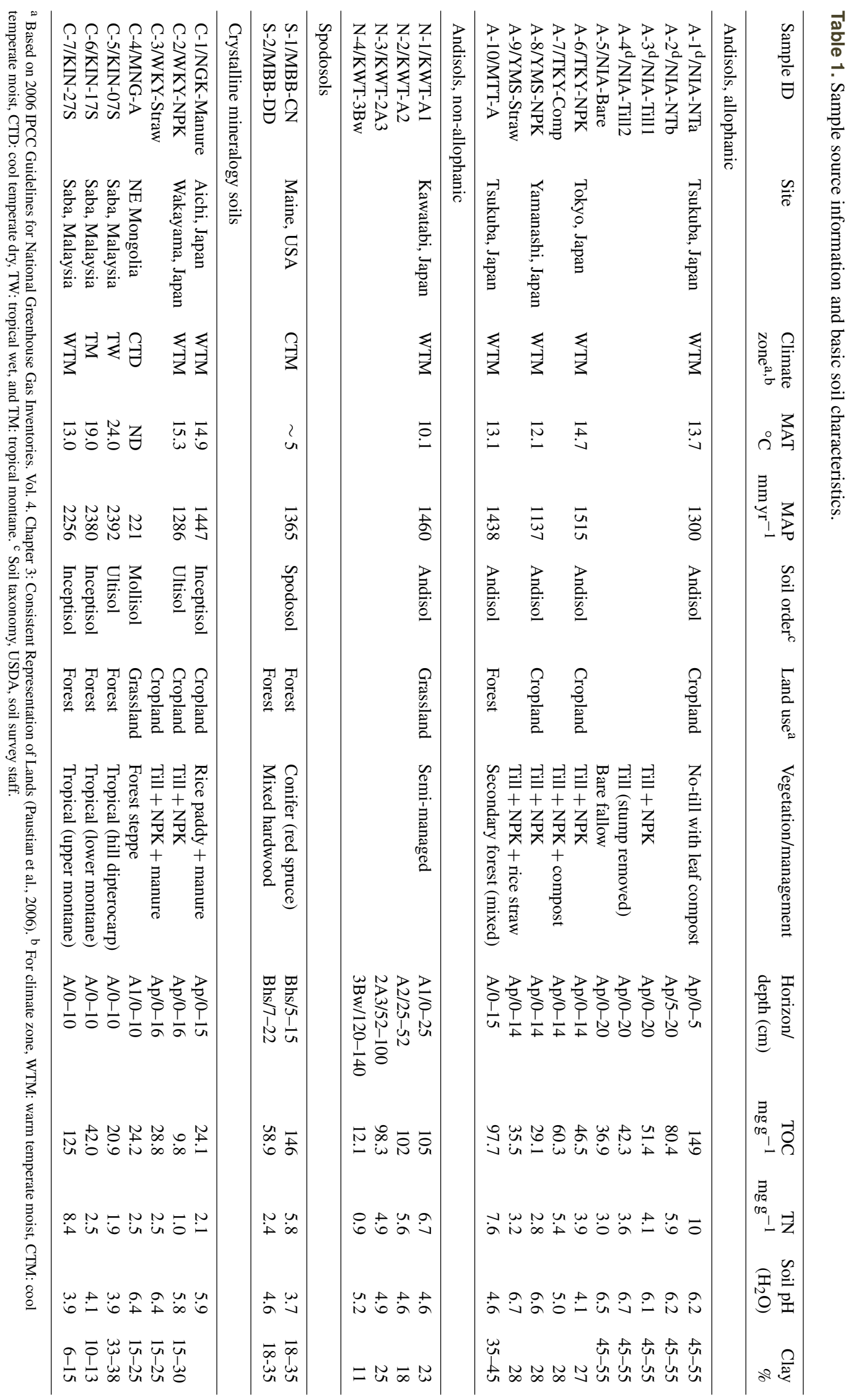


ported previously (Wagai et al., 2018). The sample group also includes two pairs of soils (A-6 vs. A-7, and A-8 vs. A-9) from other long-term field experiments of $\mathrm{OM}$ amendment and one soil from a relatively undisturbed secondary forest site.

Non-allophanic Andisol samples consist of four horizons from a well-characterized pedon (Pacllic Mdanudand) from the Field Science Center of Tohoku University, Miyagi, Japan, located on a gentle slope of a fan in mountain valleys at $190 \mathrm{~m}$ elevation maintained as grassland (Sasa nipponica). Parent material is dacitic volcanic tephra with alluvium including smectitic sedimentary rock. A2 horizon contained a key tephra (Hijiori pumice: $10 \mathrm{kyr} B \mathrm{P}$ ).

Spodic group consists from the spodic horizon from two pedons (coarse-loamy, isotic, frigid, Typic Haplorthods, developed from ca. $1 \mathrm{~m}$ thick glacial till) under coniferous and deciduous forest types in Bear Brooke Watershed, Maine, USA. Further details on the sites and soil OM characteristics can be found in Ohno et al. (2017). Major soil minerals are quartz with moderate amounts of plagioclase, K-feldspar, and hornblende (Swoboda-Colberg and Drever, 1993).

Crystalline mineralogy group consists of a range of soils relatively low in extractable $\mathrm{Fe}$ and $\mathrm{Al}$ phases or high in more stable clay-sized minerals such as kaolinite. The paddy soil (C-1) has been under seasonal flooding (May to August/September) for more than several decades. The other two soils (C-2, C-3, classified as Aquic Hapludult) are from long-term experiments of manure application. The most arid soil in our sample set is Mongolian forest steppe soil (C-4), Calcic Kastanonzems in the WRB classification system. Our A horizon sample, however, contains no carbonate (Asano et al., 2007). The other three soils are from an elevation gradient under tropical rainforest with the dominant clay mineralogy of kaolinite, gibbsite, hydroxyl-interlayered vermiculite, and quartz (C-5) and illite, kaolinite, and quartz (C-6, C-7). More details on the sites and soils are shown in Wagai et al. (2008) and Tashiro et al. (2018).

All samples were air-dried and $2 \mathrm{~mm}$ sieved prior to density fractionation and chemical analyses. Air-drying did not significantly change OM and metal distribution across density fractions, showing no irreversible aggregation by airdrying for an allophanic Andisol (Wagai et al., 2015) and presumably for the other soils. Carbon refers to organic $\mathrm{C}$ in this study as no carbonate was found in these soils.

\subsection{Physical fractionation by density}

We sorted soil particles based on particle density using sodium polytungstate (SPT-0 grade, Sometsu, Germany) to make the liquids of various densities. We employed mechanical shaking to disrupt less-stable aggregates and sequentially separated density fractions following previous studies (Crow et al., 2014; Sollins et al., 2009; Wagai et al., 2018). Most soil samples were separated into six to seven fractions $(n=18)$, while the other five samples (A-6, A-
7, A-8, A-9, C-1) examined at a later stage were fractionated into only four fractions (Table 1, also see Table A1 in Appendix A) because we learned that the main allocation pattern can be captured by four density fractions. The sieved soil samples were mixed with $1.6 \mathrm{~g} \mathrm{~cm}^{-3}$ SPT solution (soil : solution ratio $=10 \mathrm{~g}: 40 \mathrm{~mL}$ ), mechanically shaken for $30 \mathrm{~min}$ at $120 \mathrm{rpm}$, and centrifuged $(20 \mathrm{~min}, 2330 \mathrm{~g})$. The floating material $\left(<1.6 \mathrm{~g} \mathrm{~cm}^{-3}\right.$, the lowest-density fraction, F1) was collected on a $0.22 \mu \mathrm{m}$ membrane filter using a vacuum filtration system. These steps (shaking to centrifugation) were repeated three times to maximize the recovery of this fraction. The materials caught on the filter were washed with deionized water until the salt concentration of the final $50 \mathrm{~mL}$ of water reached $<50 \mu \mathrm{S} \mathrm{cm}^{-1}$ and then transferred to a beaker for oven-drying at $80^{\circ} \mathrm{C}$. After the isolation of $\mathrm{F} 1$, the remaining material in the centrifuge tube was re-suspended in $1.8 \mathrm{~g} \mathrm{~cm}^{-3}$ SPT solution, shaken again, and centrifuged. The floating materials $\left(1.6-1.8 \mathrm{~g} \mathrm{~cm}^{-3}, \mathrm{~F} 2\right)$ were transferred to $250 \mathrm{~mL}$ bottles, mixed with deionized water, and centrifuged (17000 g, 30-60 min), and then the supernatant was discarded. This process was repeated four to five times until the supernatant salt concentration reached $<50 \mu \mathrm{S} \mathrm{cm}^{-1}$ and the rinsed materials were freeze-dried. Following the same procedure, we then sequentially isolated higher-density fractions (e.g., F3: 1.8-2.0, F4: 2.0-2.25, F5: 2.25-2.5, and F6: $>2.5$ ) using correspondingly higher-density SPT solutions. To fully recover each density fraction, we repeated the steps (from shaking to the recovery of floating materials) at least three times.

The selection of cutoff density for higher-density fractions varied among the soils (Table A1). This was partly due to soil mineralogical difference (e.g., soils expected to have higher $\mathrm{Fe}$ contents had the highest-density cutoff of 2.75 instead of $\left.2.6 \mathrm{~g} \mathrm{~cm}^{-3}\right)$. The lowest-density fractions $\left(<1.6 \mathrm{~g} \mathrm{~cm}^{-3}\right)$ were oven-dried at $80^{\circ} \mathrm{C}$ instead of freeze-drying for logistical reasons. Due to the concentration of the extractable metals in this fraction, we assumed little effect of the difference in the drying method on our result interpretation. We also assume little impact of sodium polytungstate on the extractability of $\mathrm{Fe}$ and $\mathrm{Al}$ phases or the nature of soil microaggregates as the SPT solution after the density fractionation typically had a $\mathrm{pH}$ value similar to bulk soil $\mathrm{pH}$.

\subsection{Extraction of metal phases}

Bulk and density-fractionated samples were sequentially extracted by sodium pyrophosphate (PP) followed by acid oxalate in the dark (OX) and then by dithionite-citrate (DC) following Wagai et al. (2018). First, initial PP extraction was conducted at the soil: solution ratio of $100 \mathrm{mg}: 10 \mathrm{~mL}$ with $0.1 \mathrm{M}$ sodium pyrophosphate $(\mathrm{pH}=10)$ and then shaken at $120 \mathrm{rpm}$ for $16 \mathrm{~h}$. After high-speed centrifugation $(29000 \mathrm{~g}$, $45 \mathrm{~min}$ ), an aliquot of the extract was immediately taken for dissolved C, N, and metal analyses. Second, the residue after discarding the remaining supernatant was re-suspended 
and extracted with $10 \mathrm{~mL}$ of $0.2 \mathrm{M}$ acidified sodium oxalate solution $(\mathrm{pH}=3.0)$, shaken at $120 \mathrm{rpm}$ for $4 \mathrm{~h}$ in the dark. The conventional acid oxalate method (Loeppert and Inskeep, 1996) was modified by replacing ammonium oxalate with sodium oxalate to allow the direct quantification of co-dissolved $\mathrm{N}$ while achieving the same extraction efficiency of $\mathrm{Fe}, \mathrm{Al}$, and $\mathrm{Si}$ (Wagai et al., 2013). After the high-speed centrifugation, an aliquot of the extract was immediately diluted for metal and $\mathrm{N}$ analyses to avoid precipitation. Third, $0.1 \mathrm{~g}$ of sodium dithionite was added to the remaining residue and mixed with $10 \mathrm{~mL}$ of $22 \%$ (by wt) sodium citrate. The mixture was shaken for $16 \mathrm{~h}$ and centrifuged under the same condition as above. All extractions were done at room temperature $\left(20-22^{\circ} \mathrm{C}\right)$. We did not filter the supernatants after the high-speed centrifugation of PP extracts as our pilot test showed no systematic decrease in dissolved organic $\mathrm{C}$ and metals by vacuum filtration using a $0.025 \mu \mathrm{m}$ pore-sized membrane (Millipore, VSWP, Bedford, MA, USA). Similarly, no filtration was done for OX and DC extracts after the high-speed centrifugation.

\subsection{Chemical analyses}

The concentrations of $\mathrm{Fe}, \mathrm{Al}, \mathrm{Si}$, and $\mathrm{Mn}$ in the extracts of PP, OX, and DC were analyzed by inductively coupled plasma-optical emission spectroscopy (Vista-Pro, Agilent, CA, USA). The metal analyses were done for all fractions. The only exception is the lowest-density fraction from three soil samples (A-5, N-4, C-2) where low mass recovery prevented the extractions. Analytical errors associated with our density fractionation were sufficiently low for $\mathrm{C}, \mathrm{N}$, and the extractable metals ( $<12 \%$, Wagai et al., 2015) to allow testing of our hypothesis. When assessing the role of extractable metal as a whole, we summed weight-based concentrations of $\mathrm{Al}$ and $\mathrm{Fe}$ as " $\mathrm{Al}+0.5 \mathrm{Fe}$ " to approximately normalize the atomic mass difference between $\mathrm{Al}$ and $\mathrm{Fe}$ for graphical and statistical purposes. This allows us to compare the metal concentration with $\mathrm{C}$ on a weight basis. We also reported some values including the stoichiometric relationships among the target elements (e.g., $\mathrm{Al}$ : $\mathrm{Si}$ ratio) on a molar basis to allow comparison with other literature values.

Co-dissolved organic $\mathrm{C}$ and $\mathrm{N}$ by PP extraction and the $\mathrm{N}$ by OX extraction were quantified by a TOC analyzer (Shimadzu TOC-V/TNM1, Kyoto, Japan). Dissolved organic C (DOC) was measured as non-purgeable organic $\mathrm{C}$ after acidification and $\mathrm{C}$-free air purging. Total dissolved $\mathrm{N}$ was measured by a chemiluminescence accessory. This method, including the caveats on this technique, was discussed elsewhere (Wagai et al., 2013). Because quantifying the soil C in an oxalate extract is not possible, we estimated the $\mathrm{C}$ associated with $\mathrm{OX}$-extractable mineral phases $\left(\mathrm{DOC}_{\mathrm{OX}}\right)$ by multiplying total dissolved $\mathrm{N}$ concentration in $\mathrm{OX}$ extract by the $\mathrm{C}: \mathrm{N}$ for each density fraction. This estimation assumes that the $\mathrm{OM}$ dissolved by the oxalate extraction has the same $\mathrm{C}: \mathrm{N}$ ratio as that in bulk fraction. This assumption cannot be fully justified but would be a reasonable approximation for the purpose of assessing the trends because a plot of the $\mathrm{C}: \mathrm{N}$ ratio of PP-extractable phase against that of bulk soil $\mathrm{C}: \mathrm{N}$ (regression through the origin) showed a significant positive correlation $\left(r^{2}=0.89, p<0.0001\right)$ with the slope close to 1 (1.25 with $95 \%$ confidence interval of 1.15-1.32). Total organic $\mathrm{C}$ and $\mathrm{N}$ concentrations in the isolated fractions and bulk samples were analyzed by an elemental analyzer (Flash2000 Thermo Fisher Scientific Inc., USA). All the elemental concentrations from the three extractions conducted were shown in Table A1.

\subsection{Extractable elements expressed in two ways}

The extractable elements were examined for their concentrations within each density fraction and across the fractions. First, we assessed the concentration of the elements for each extractable phase per density fraction mass (e.g., $\mathrm{mg} \mathrm{Fe}^{-1}$ fraction). Second, we also assessed the distribution of the elements per bulk soil mass (e.g., $\mathrm{mg} \mathrm{Fe}^{-1}$ bulk soil) by multiplying the elemental concentration per fraction (mg Fe $\mathrm{g}^{-1}$ fraction) by the mass proportion for the respective fraction in bulk soil ( $\mathrm{g}$ fraction $\mathrm{g}^{-1}$ bulk soil).

\subsection{Peak density determination}

For each soil sample, we determined the particle density at which the metal concentration from each extraction was highest (termed "peak density") using two approaches. First, we simply selected the density fraction where the metal concentration was the highest among the fractions for a given soil and used its midpoint (e.g., $2.1 \mathrm{~g} \mathrm{~cm}^{-3}$ for $2.0-$ $2.2 \mathrm{~g} \mathrm{~cm}^{-3}$ fraction) as the peak density. The actual peak density is not necessarily its mean, especially for the samples separated into a smaller number of fractions. Thus, as a second approach, we also estimated the peak density by fitting a normal distribution curve to the metal concentrations per fraction against particle density for each soil (Fig. A1 left panels). The majority of soil samples fitted well, though we had to remove the data points from the lowest- and highest-density fractions in some cases (Fig. A1). For instance, OX- and DC-extractable metal concentrations in the highest-density fractions were quite high for non-allophanic Andisol samples due presumably to magnetite. Thus, those data points were not used for the fitting. Similarly, we eliminated the lowest one or two density fractions of PP- and OX-extractable metal concentration data from six samples from the crystalline mineralogy group. Eliminating these data points (Fig. A1) was done only to enable fitting of a normal distribution (on average $r^{2}=0.90-0.98$, Fig. A2a). The mean of the normal distribution for each extraction/soil was used as the second estimate of peak density. We also determined the mass-weighted particle density at which the metal was most concentrated. After calculating the metal distribution along the density gradient (i.e., metal concentra- 
tion $\times$ mass fraction), the two approaches above were applied to determine the peak density for each soil sample and each extractable metal phase. A normal distribution fitted well for most samples (Figs. A1 right panels, A2b).

\subsection{Scanning electron microscopy}

Isolated density fractions from selected soil samples were observed by SEM (SU1510, Hitachi high-technologies, Tokyo, Japan). Subsets of freeze-dried density fractions were re-dispersed in ultrapure water by weak sonication $\left(<10 \mathrm{~J} \mathrm{~mL}^{-1}\right)$, deposited on carbon tape, and were Pt-Pd coated prior to the observation.

\subsection{Statistics}

Linear regression analyses between extractable metals and DOC were done using JMP software (version 8.0.1, SAS Institute, Cary, NC, USA). Density-dependent change in the proportion of total $\mathrm{C}$ in each fraction explained by the association with PP- and OX-extractable phases ([DOC $\mathrm{PP}+$ $\left.\mathrm{DOC}_{\mathrm{OX}}\right] / \mathrm{TC}$ ) was modeled for each soil group using polynomial functions using JMP software.

\section{Results}

\subsection{Recovery after sequential density fractionation}

Our density fractionation procedure showed a largely reasonable recovery of mass, $\mathrm{C}$, and $\mathrm{N}$ for the 23 soil samples studied (Table 2). While the recovery of the metals assessed by PP-, OX-, and DC sequential extractions was generally good, the variation among the soils was larger (Table 2), as some soil samples and metal phases showed poor recoveries. Possible sources of errors are (i) the small sample mass used for the extractions, (ii) additive errors from the sequential extractions, and (iii) the small sizes of targeted pools. For example, the recovery worsened for DC-extractable $\mathrm{Al}$ and $\mathrm{Si}$ pools following PP and OX extractions. Incomplete removal of colloidal $\mathrm{Fe}$ and $\mathrm{Al}$ phases likely explains higher metal recovery from Andisol samples $(118 \pm 36 \%)$ compared to non-Andisol samples $(84 \pm 12 \%)$ in PP extraction. The factors affecting the poor recovery with the sequential extraction approach were discussed in more detail elsewhere (Wagai et al., 2018). We considered the obtained recoveries (Table 2) to be tolerable for assessing the general patterns of the metals and $\mathrm{OM}$ across the density fractions.

\subsection{Concentration of $\mathrm{C}, \mathrm{N}$, and extractable metals along the particle density gradient}

The $\mathrm{C}$ concentration was highest in the lowest-density fraction (238-443 $\mathrm{mg} \mathrm{Cg}^{-1}$ fraction), declined with increasing density up to ca. $2.5 \mathrm{~g} \mathrm{~cm}^{-3}$, and remained low (1.5$7.1 \mathrm{mg} \mathrm{C} \mathrm{g}^{-1}$ fraction) at higher densities for each of the studied soils (Fig. A3a). Similarly, C:N ratio showed a progres- sive decline with increasing density in each soil (Fig. A3b). While the majority of the soil samples showed very low $\mathrm{C}$ concentration and $\mathrm{C}: \mathrm{N}$ ratio in the fractions higher than ca. $2.5 \mathrm{~g} \mathrm{~cm}^{-3}$, a few samples showed a slight increase towards the highest-density fraction.

The extractable metal concentration $(\mathrm{Al}+0.5 \mathrm{Fe})$ generally showed a unimodal pattern along the particle density gradient with some distinct patterns among the four soil groups (Fig. 1; also see Fig. A1 left panels for individual soils). The allophanic Andisol group showed higher OXand DC-extractable metals (metalox, metal ${ }_{\mathrm{DC}}$ ), especially in a meso-density (intermediate) range $\left(1.8-2.4 \mathrm{~g} \mathrm{~cm}^{-3}\right.$ ) up to $78.3 \mathrm{mg} \mathrm{g}^{-1}$ fraction $\left(1.46 \mathrm{mmol} \mathrm{g}^{-1}\right.$ fraction) for metal $\mathrm{OX}$ and $27.2 \mathrm{mg} \mathrm{g}^{-1}$ fraction $\left(0.38 \mathrm{mmol} \mathrm{g}^{-1}\right.$ fraction) for metal ${ }_{\mathrm{DC}}$, whereas non-allophanic Andisol and Spodosol groups were characterized by high concentrations of PP-extractable metals (metal $\mathrm{PP}$ ) up to $53.2 \mathrm{mg} \mathrm{g}^{-1}$ fraction $\left(1.97 \mathrm{mmol} \mathrm{g}^{-1}\right.$ fraction. As expected, the crystalline mineralogy group showed the lowest levels of metal ${ }_{P P}$ and metal $O X$ with moderate amounts of metal ${ }_{\mathrm{DC}}$ from highly weathered soil samples. Two exceptions to the general unimodal pattern were present. For metal ${ }_{P P}$, three soil samples showed their peak metal concentrations at the lowest density. For metaloX, three samples of non-allophanic Andisols showed the highest metal (especially $\mathrm{Fe}$ ) concentrations at the highest density due presumably to the presence of Fe-bearing primary minerals such as magnetite. Even in the soils relatively low in specific metal phases (e.g., the crystalline mineralogy group low in metal $\mathrm{PP}$ and metalox, and the non-allophanic Andisol and Spodosol groups low in metal ${ }_{\mathrm{OX}}$ and metal ${ }_{\mathrm{DC}}$ ), the highest metal concentrations were found at a meso-density range (Fig. A1 left panels).

Similar patterns were shown when assessing the distribution of the metals along the density gradient by accounting for mass distribution (Fig. A1 right panels). The unimodal pattern remains for most samples, indicating that the major portions of respective metal phases accumulated in a mesodensity range. However, the dominant metal phase clearly differed among the soil groups. In the allophanic Andisol group, $63 \pm 9 \%$ of the total extractable metal was present in OX-extractable phase. On the other hand, the non-allophanic Andisol and Spodosol groups showed that $59 \pm 25 \%$ and $75 \pm$ $14 \%$ of the total extractable metals, respectively, were accounted for by PP-extractable phase. In the crystalline mineralogy group, DC-extractable phase accounted for higher portions $(41 \pm 14 \%)$ of the total extractable metal.

The comparison of extractable $\mathrm{Fe}$ and $\mathrm{Al}$ among the three extractions generally showed the increasing dominance of low-crystallinity phases (PP- and OX-extractable phases) in lower-density fractions (Fig. A4). The proportion of total extractable Fe present as $\mathrm{Fe}_{\mathrm{PP}}$ and $\mathrm{Fe}_{\mathrm{OX}}$ showed a clear decline for all four soil groups, with a note that the highest-density fractions in Andisol samples were due presumably to magnetite. A similar declining trend was found for the extractable $\mathrm{Al}$ phases. Although minor in quantity, the extractable $\mathrm{Mn}$ 
Table 2. Recoveries (percentages) of mass, $\mathrm{C}, \mathrm{N}$, and the metals dissolved by initial pyrophosphate (PP) and subsequent acid oxalate (OX) and dithionite-citrate (DC) extractions from the density fractions, expressed as percentage relative to the whole soil. Values show means (standard deviations) of all soils and separately for Andisols (allophanic and non-allophanic Andisols) and non-Andisols (Spodosols and crystalline mineral soils).

\begin{tabular}{|c|c|c|c|c|c|c|c|c|c|}
\hline \multirow[t]{2}{*}{ Soil group } & \multirow[t]{2}{*}{ Mass } & \multirow[t]{2}{*}{$\mathrm{C}$} & \multirow[t]{2}{*}{$\mathrm{N}$} & \multirow{2}{*}{$\begin{array}{r}\text { PP extr. } \\
\mathrm{Al}+0.5 \mathrm{Fe}\end{array}$} & \multirow{2}{*}{$\begin{array}{r}\text { OX extr. } \\
\mathrm{Al}+0.5 \mathrm{Fe}\end{array}$} & \multirow{2}{*}{$\begin{array}{r}\text { DC extr. } \\
\mathrm{Al}+0.5 \mathrm{Fe}\end{array}$} & \multicolumn{3}{|c|}{ Sum of PP, OX, and DC extractions } \\
\hline & & & & & & & $\mathrm{Al}$ & $\mathrm{Fe}$ & $\mathrm{Si}$ \\
\hline All soils $(n=23)$ & $99.8(2.9)$ & $97.5(9.5)$ & $95.6(10.6)$ & $104.6(33.3)$ & $98.8(20.5)$ & $86.4(16.9)$ & $88.8(16.0)$ & $94.4(11.2)$ & $93.6(20.4)$ \\
\hline Volcanic $(n=14)$ & $101.3(1.9)$ & $102.2(6.7)$ & $101.3(7.4)$ & $117.9(36.0)$ & $104.9(22.7)$ & $86.3(18.4)$ & $95.4(13.4)$ & $99.3(7.5)$ & $101.9(21.5)$ \\
\hline Non-volcanic $(n=9)$ & $96.8(2.1)$ & $90.3(8.9)$ & $86.8(8.9)$ & $83.9(12.0)$ & $89.4(12.5)$ & $86.7(15.5)$ & $78.7(15.0)$ & $86.7(12.0)$ & $80.8(9.3)$ \\
\hline
\end{tabular}

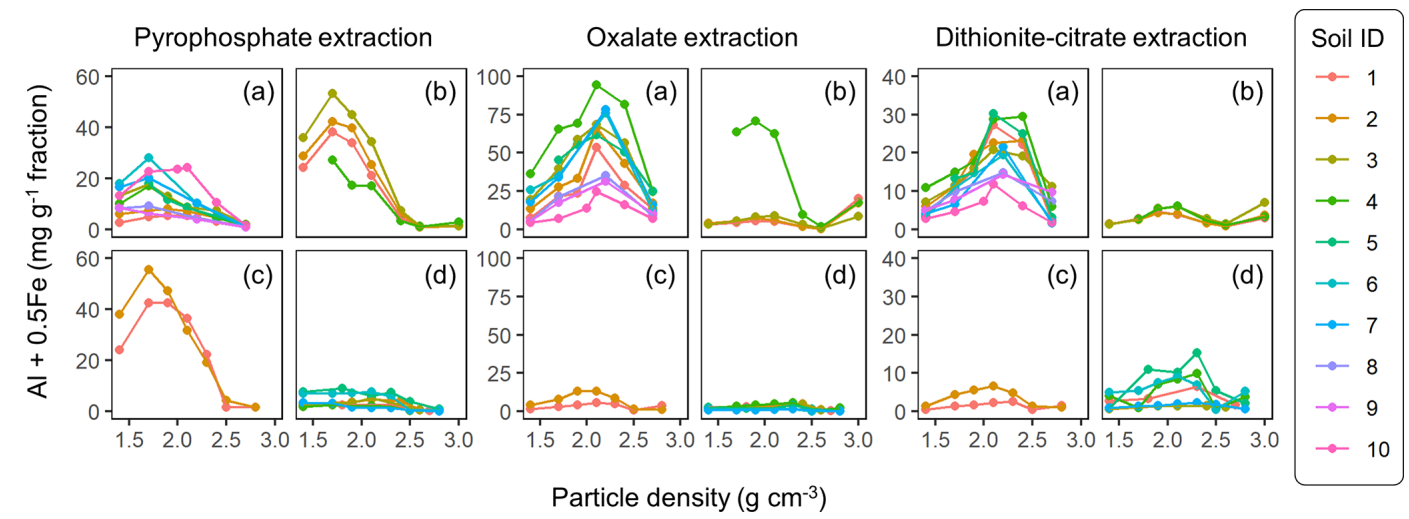

Figure 1. The concentrations of pedogenic metal $(\mathrm{Al}+0.5 \mathrm{Fe})$ per fraction along the density gradient for allophanic Andisol group (a), non-allophanic Andisol group (b), Spodosol group (c), and crystalline mineral group (d). The metal extracted by initial pyrophosphate (left panels), subsequent acid oxalate (central panels), and final dithionite-citrate reagents (right panels) are shown. Each symbol represents an individual soil sample. Sample number (1-10) on the right corresponds to sample ID for each soil group in Table 1.

also showed a similar pattern to Fe in line with the generally positive correlation between extractable Fe and Mn (data not shown). The extractable Si showed less clear patterns along the density gradient (Fig. A4).

The Al:Fe molar ratio was highest in the metalpP phase $(4.7 \pm 4.3$, mean $\pm \mathrm{SD})$, followed by the metal $\mathrm{OX}$ phase $(2.6 \pm 1.9)$ and, expectedly, lowest in the metal ${ }_{D C}$ phase $(0.4 \pm 0.3)$ across all soils and their fractions. Several patterns were identified (Fig. A5). First, relative enrichment of Fe in metal ${ }_{O X}$ and metal ${ }_{D C}$ phases was evident in the highestdensity fractions due presumably to the dissolution of crystalline $\mathrm{Fe}$ oxides. Second, from the low to meso density up to $2.3 \mathrm{~g} \mathrm{~cm}^{-3}$, the $\mathrm{Al}: \mathrm{Fe}$ ratio remained relatively constant with some exceptions. The allophanic Andisol group showed relative $\mathrm{Al}$ enrichment at around $1.8 \mathrm{~g} \mathrm{~cm}^{-3}$ for the PP-extractable phase and at around $2.0-2.3 \mathrm{~g} \mathrm{~cm}^{-3}$ for the metal $\mathrm{OX}$ phase. The non-allophanic Andisol group showed the Al enrichment towards low density for all extractable phases. For the other soil groups, similar Al enrichment was found in some samples, while others showed constant $\mathrm{Al}: \mathrm{Fe}$ ratios. Nevertheless, the density at which the metal concentration was highest among the fractions (i.e., peak density) was quite similar between Fe and $\mathrm{Al}$ (Table A1). We thus examined the extractable $\mathrm{Fe}$ and $\mathrm{Al}$ together (i.e., $\mathrm{Al}+0.5 \mathrm{Fe}$ ) for most of the subsequent analyses.
The extractable $\mathrm{Al}$ in most soils and fractions was more enriched relative to the corresponding extractable $\mathrm{Si}$. The $\mathrm{Al}$ : Si molar ratio was $9.6 \pm 16.9($ mean $\pm \mathrm{SD})$ for metal $\mathrm{PP}$, $3.6 \pm 2.1$ for metal ${ }_{\mathrm{OX}}$, and $1.1 \pm 0.9$ for the metal ${ }_{\mathrm{DC}}$ phase. Concerning density-dependent patterns, the $\mathrm{Al}: \mathrm{Si}$ ratio in PP- and OX-extractable phases was higher at lower-density fractions for the non-allophanic Andisol and Spodosol groups, whereas a weak opposing trend was shown in the DC-extractable phase in the crystalline mineralogy group (Table A1).

We further compared the peak location in the unimodal metal concentration patterns along the density gradient among the studied soils (Figs. 1, A1 left panels). While the peak densities for all extractable metals were found at a meso-density range for all soil samples studied, we found important differences among the extractable phases. The peak densities of the metal $P P$ phase were more variable compared to the metal $\mathrm{OX}$ and metal ${ }_{\mathrm{DC}}$ phases (Fig. 2). In particular, two C-rich soils (C-3, C-7) had the fitted peak density of metalPP at $<1.5 \mathrm{~g} \mathrm{~cm}^{-3}$ (Fig. A1). The medians (and lower/upper quartiles) of the measured peak density among the 23 soil samples for PP-, OX- and DC-extractable metal phases were 1.7 (1.7-2.0), $2.1(2.1-2.3)$, and $2.2(2.1-2.3) \mathrm{g} \mathrm{cm}^{-3}$, respectively (Fig. 2). Similarly, their means were 1.8, 2.2, and $2.2 \mathrm{~g} \mathrm{~cm}^{-3}$. The peak densities estimated by the nor- 


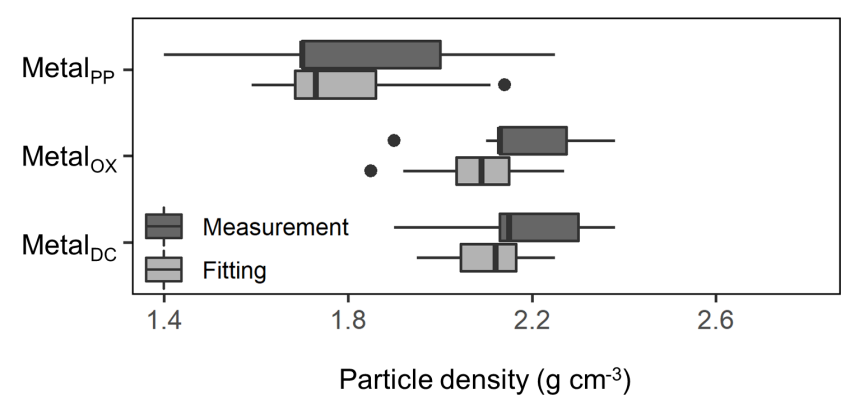

Figure 2. Boxplot showing the median and variation of densities at which the concentration of pedogenic metal $(\mathrm{Al}+0.5 \mathrm{Fe})$ was the highest across the 23 studied soils. The peak density was determined for all three extractions (PP, OX, and DC) for each soil based on measurements (light color) and normal distribution fitting (dark color).

mal distribution fitting also showed comparable values. Thus, the peak densities of all three extractable phases were $<$ $2.3 \mathrm{~g} \mathrm{~cm}^{-3}$. The metalpp phase showed its peak consistently lower by $0.3-0.4 \mathrm{~g} \mathrm{~cm}^{-3}$ than the metal $\mathrm{OX}$ and metal $\mathrm{DC}$ phases (Figs. 1 and 2).

The concentrations of $\mathrm{C}$ co-dissolved during the initial $\mathrm{PP}$ and subsequent $\mathrm{OX}$ extractions ( $\mathrm{DOC}_{\mathrm{PP}}$ and $\mathrm{DOC}_{\mathrm{OX}}$ ) correlated positively with the extractable metal concentrations (Fig. 3a-f). Coefficients of determination were highest for $\mathrm{Al}_{\mathrm{PP}}+0.5 \mathrm{Fe}_{\mathrm{PP}}\left(r^{2}=0.75, p<0.0001\right)$ followed by $\mathrm{Al}_{\mathrm{PP}}(0.66,<0.0001)$ and then $\mathrm{Fe}_{\mathrm{PP}}(0.56,<0.0001)$. Importantly, the positive $\mathrm{DOC}_{\mathrm{PP}}-\mathrm{Al}_{\mathrm{PP}}$ and/or $\mathrm{DOC}_{\mathrm{PP}}-\mathrm{Fe}_{\mathrm{PP}}$ relationships persisted across the density fractions within each soil, although the correlation was not significant for 5 out of the 23 soil samples (Fig. A6). The $\mathrm{DOC}_{\mathrm{PP}}$ : Al $\mathrm{l}_{\mathrm{PP}}$ mass ratio (i.e., slope of the regression lines) ranged from 2.9 to 28.2 (mean: 7.9, SE: 1.6), which is equivalent to the mean molar ratio of 17.8 (SE: 14.6).

Similarly, the organic matter co-dissolved by the oxalate extraction $\left(\mathrm{DOC}_{\mathrm{OX}}\right)$ was positively related to metalox owing largely to the allophanic Andisol samples (Fig. 3d-f). Simple linear regression of $\mathrm{DOC}_{\mathrm{OX}}$ against $\mathrm{Al}_{\mathrm{OX}}, \mathrm{Fe}_{\mathrm{OX}}$, and $\mathrm{Al}_{\mathrm{OX}}+0.5 \mathrm{Fe}_{\mathrm{OX}}$ concentrations among all samples showed the strongest control by $\mathrm{Al}_{\mathrm{OX}}\left(r^{2}=0.66\right)$ followed by $\mathrm{Al}_{\mathrm{OX}}+0.5 \mathrm{Fe}_{\mathrm{OX}}\left(r^{2}=0.60\right)$ and then Fe $\mathrm{OX}\left(r^{2}=0.39, p<\right.$ $0.0001)$. When assessed for individual soils, the positive $\mathrm{C}-$ metal relationship (mostly only with $\mathrm{Al}_{\mathrm{OX}}$ ) persisted for 8 out of the 14 Andisol samples, but no positive relationship was present for the rest of the soils (Fig. A7). The range for the $\mathrm{DOC}_{\mathrm{OX}}$ : $\mathrm{Al}_{\mathrm{OX}}$ mass ratio of the eight samples was 0.13-0.34 (molar $\mathrm{DOC}_{\mathrm{OX}}$ : $\mathrm{Al}_{\mathrm{OX}}$ ratio of $0.29-0.76$ ), and that of $\mathrm{DOC}_{\mathrm{OX}}:\left(\mathrm{Al}_{\mathrm{OX}}+0.5 \mathrm{Fe}_{\mathrm{OX}}\right)$ was $0.11-0.22$ (molar $\mathrm{DOC}_{\mathrm{OX}}: \mathrm{Al}_{\mathrm{OX}}+\mathrm{Fe}_{\mathrm{OX}}$ ratio of $\left.0.26-0.49\right)$ for these Andisol samples (data not shown). These ratios were roughly 10-50fold lower than that from the PP-extractable phase.

The proportion of total $\mathrm{C}$ in each density fraction codissolved by initial PP and subsequent OX extractions (ex- pressed as the sum of PP- and OX-extractable C) showed an increasing trend with increasing particle density (Fig. 4). Despite high variability especially towards higher-density fractions, the increasing trend with density was fitted by a polynomial curve for each of the four soil groups separately (Table A2). The three soil groups with high extractable metals tended to have higher proportions of extractable $\mathrm{C}$ compared to the crystalline mineralogy group. The allophanic Andisol group, which was characterized by higher $\mathrm{Al}_{\mathrm{OX}}$ and $\mathrm{Fe}_{\mathrm{OX}}$ concentrations, showed that appreciable amounts of OM were co-dissolved by the dissolution of metalox phase (Fig. 4a). In contrast, the non-allophanic Andisols and Spodosol groups showed that nearly all the extractable $\mathrm{C}$ was released by the initial PP extraction. The non-allophanic Andisol group with characteristically high $\mathrm{Al}_{\mathrm{PP}}$ and $\mathrm{Fe}_{\mathrm{PP}}$ concentrations showed that a quarter up to nearly all of the $\mathrm{C}$ present in the higher-density fractions was co-dissolved by the initial PP extraction (Fig. 4b).

\subsection{Distribution of mass, organic matter and extractable metal phases along the density gradient}

The density fraction which accounted for the largest portion of bulk soil mass was in the $2.2-2.6 \mathrm{~g} \mathrm{~cm}^{-3}$ density range, and its median (and lower-upper quartiles) was 2.5 (2.22.6) $\mathrm{g} \mathrm{cm}^{-3}$ among the 23 soil samples (Fig. 5). Carbon distribution, calculated by multiplying the $\mathrm{C}$ concentration by the fractional mass for each density fraction, showed its peak in significantly lower yet still meso-density range (Fig. 5) with the median of $2.1(1.9-2.2) \mathrm{g} \mathrm{cm}^{-3}$. The data points at $1.4 \mathrm{~g} \mathrm{~cm}^{-3}$ were from three samples (A-1, S-1, and C-7) with very high total $\mathrm{C}$ values due to high $\mathrm{OM}$ input or reduced decomposition under cooler climate.

The extractable metals were also mainly concentrated in the meso-density range (Figs. A1 left, 5b), which is statistically indistinguishable from $\mathrm{C}$ peak as a whole sample set $(n=23)$. The medians (and lower-upper quartiles) of the peak density for the PP-, OX-, and DC-extractable phases were $2.1(2.1-2.2), 2.1(2.1-2.3)$, and $2.2(2.1-2.4) \mathrm{g} \mathrm{cm}^{-3}$, respectively. In contrast with the concentration-based patterns (Fig. 2), no clear difference was found between PP and the other two extractions due to the small mass contribution of the lower-density fractions where PP-extractable metal concentration was higher (Fig. A1a).

\subsection{SEM observation of meso-density fractions}

A clear shift in dominant particle type from plant detritus (POM) in the lowest-density fraction to aggregated particles in meso-density fractions, and finally to coarse mineral grains in the highest-density fraction, was observed for the three selected soils, one from the Spodosol and two from the crystalline mineralogy group (Fig. 6). The size of these particles ranged from a few tens to hundreds of micrometers in diameter. Similar density-dependent changes were 

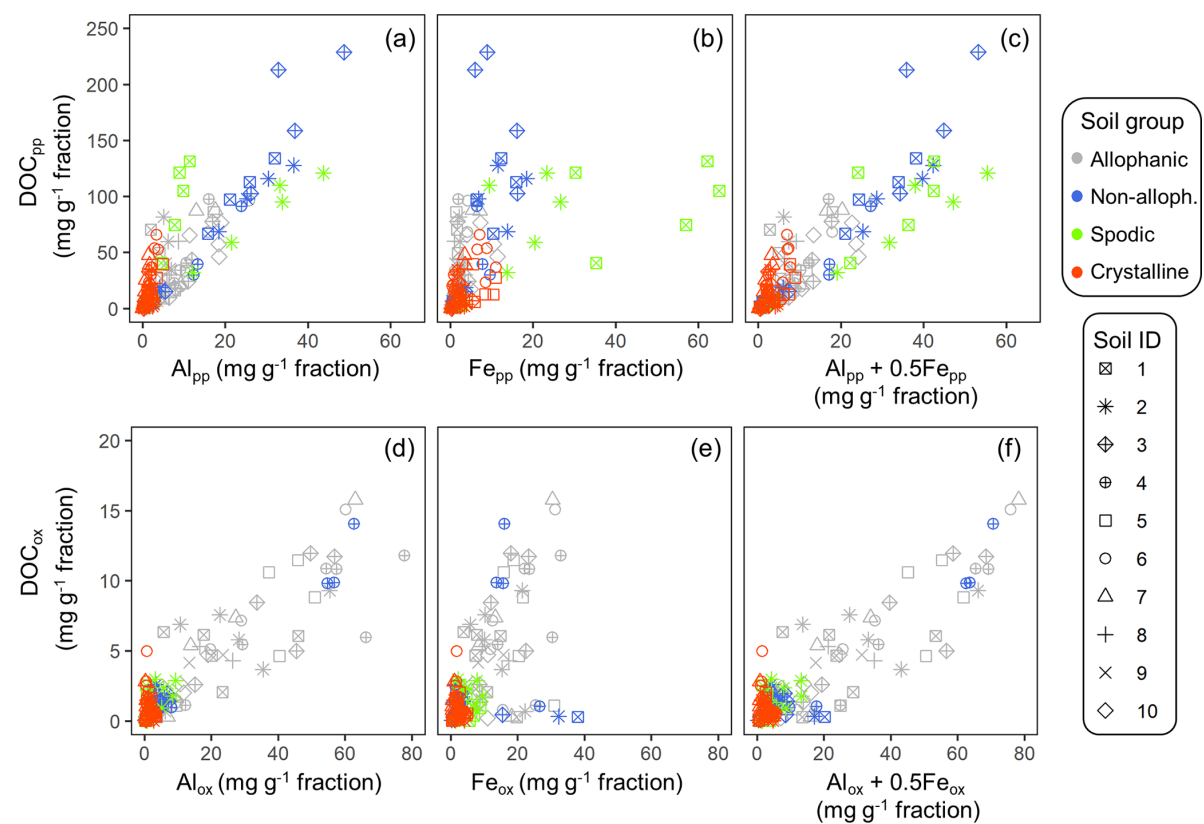

Figure 3. Scatter plot of extractable metals and co-dissolved organic C (DOC) for the density fractions from the studied soils. Pyrophosphateextractable $\mathrm{Al}(\mathbf{a}), \mathrm{Fe}(\mathbf{b})$, and $\mathrm{Al}+0.5 \mathrm{Fe}$ (c) against $\mathrm{DOC}_{\mathrm{OX}}$ in the upper panel. Oxalate-extractable $\mathrm{Al}(\mathbf{d}), \mathrm{Fe}(\mathbf{e})$, and $\mathrm{Al}+0.5 \mathrm{Fe}(\mathbf{f})$ against $\mathrm{DOC}_{\mathrm{OX}}$ in the lower panel. Symbol color distinguishes the four soil groups and its shape corresponds to sample ID in Table 1.
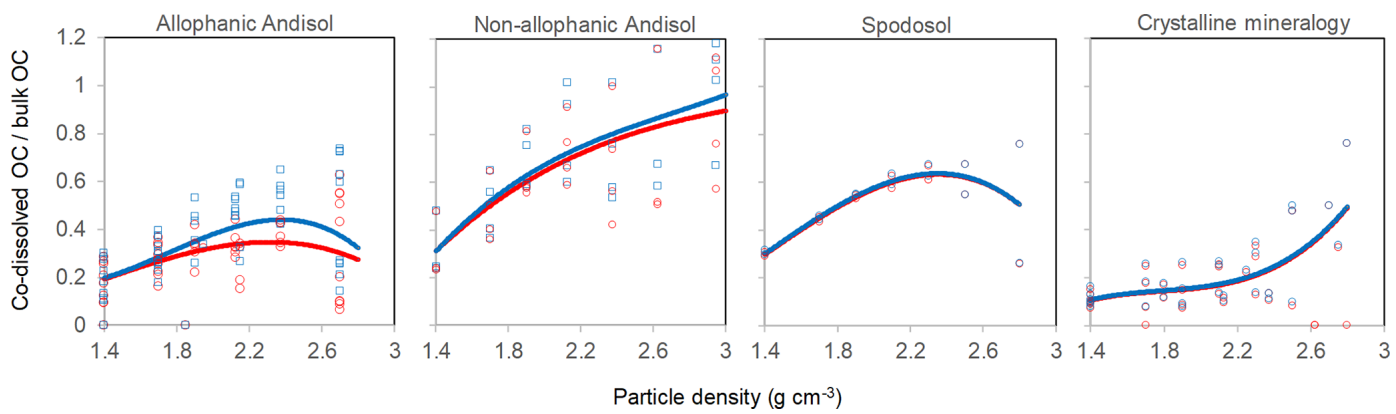

Figure 4. Proportions of bulk $\mathrm{C}$ in each density fraction co-dissolved by initial pyrophosphate extraction alone (red circle) and combined with subsequent acid oxalate extraction (blue rectangle), with polynomial fitting curves, for each soil group.

previously observed for one of the allophanic Andisols (A3, Table 1, Wagai et al., 2015). Four density fractions (1.8$2.6 \mathrm{~g} \mathrm{~cm}^{-3}$ ) where the majority of metals and $\mathrm{OM}$ reside were assessed by SEM in detail. In all three soils, 1.8-2.0 and $2.0-2.2 \mathrm{~g} \mathrm{~cm}^{-3}$ fractions were more abundant in fragmented POM, which was mostly enmeshed in aggregates or coated with clay-size grains (Fig. 6a, b, e, f, i, j), while the materials in the $2.2-2.4 \mathrm{~g} \mathrm{~cm}^{-3}$ fraction appeared largely aggregated with no visible POM (Fig. 6c, g, k). At a closer look at the surface of these aggregates and POM, clay-platelet-like features $(<5 \mu \mathrm{m})$ were visible (Fig. $6 \mathrm{a}-\mathrm{k}$, magnified views). The next heavier fraction $\left(2.4-2.6 \mathrm{~g} \mathrm{~cm}^{-3}\right)$ was more abundant in coarser mineral grains with clean surfaces, although some grains in this fraction were aggregated or showed rough surfaces (Fig. 6d, h, 1, magnified views).

\section{Discussion}

\subsection{Fe and Al phases extracted by the three reagents}

The metals released by PP, OX, and DC extractions only roughly correspond to specific metal phases present in the soil as these extractions are not highly selective (Parfitt, 2009; Rennert, 2019). This approach, nevertheless, remains important as the extractable metal contents often show significant correlation with soil $\mathrm{C}$ storage and turnover times (Masiello et al., 2004; Percival et al., 2000; Porras et al., 2017; Torn et al., 1997; Wada and Higashi, 1976). It is thus critical to elucidate the nature of these metal phases including their localization, which aids in resolving the gap between commonly used mathematical models and the current understanding of soil C dynamics (Blankinship et al., 2018). 

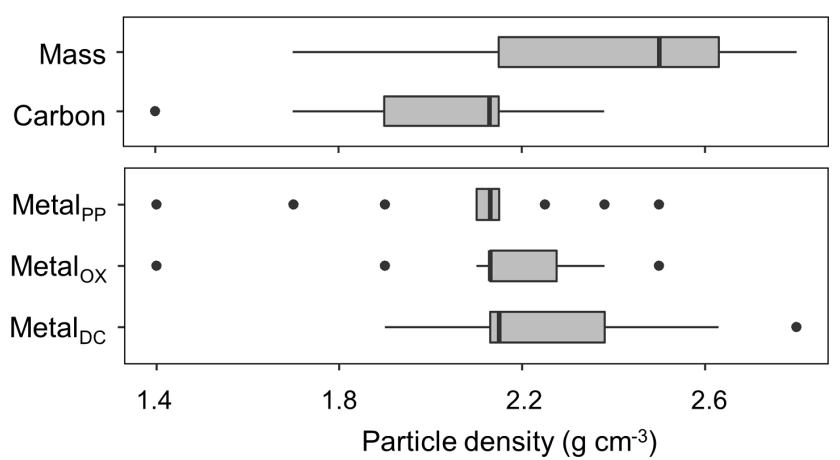

Figure 5. Boxplot showing the median and distribution of the densities at which the distribution of mass, $\mathrm{C}$, and pedogenic metal $(\mathrm{Al}+0.5 \mathrm{Fe})$ extracted by the three extractants (PP, OX, and DC) were the highest among the 23 studied soils.

Compared to common single extraction, a sequential extraction approach may allow better assignments of different $\mathrm{Fe}$ and Al phases (Dai et al., 2011; Shang and Tiessen, 1998). It is generally assumed that the PP extraction mainly dissolves organo-metal complexes (Bascomb, 1968; Takahashi and Dahlgren, 2016), whereas the OX and DC extractions target dissolution of short-range-order minerals and crystalline iron oxides, respectively (e.g., Inagaki et al., 2020; Lawrence et al., 2015; Shang and Tiessen, 1998). Pyrophosphate extraction data require particularly cautious interpretation due to the OM dissolution by high alkalinity $(\mathrm{pH} \mathrm{10)}$ and the dispersion or dissolution of colloidal and low-crystallinity $\mathrm{Fe}$ and $\mathrm{Al}$ oxide phases (Coward et al., 2018; Kaiser and Zech, 1996; Lawrence et al., 2015; Schuppli et al., 1983; Shang and Tiessen, 1998; Wagai et al., 2013). However, the significant $\mathrm{DOC}_{\mathrm{PP}}-$ metal $\mathrm{PP}$ (especially $\mathrm{DOC}_{\mathrm{PP}}-\mathrm{Al}_{\mathrm{PP}}$ ) correlations found across the soils (Fig. 3a-c) and, to a limited extent, among the fractions within soils (Fig. A6), imply the predominance of strong OM-metal association phases such as organo-metal complexes in PP extracts because the potential artifacts, if occurring significantly, would have prevented the emergence of such a proportional relationship. Most of the studied soils showed significant $\mathrm{C}$-metal correlation with high $\mathrm{DOC}_{\mathrm{PP}}$ : $\mathrm{Al}_{\mathrm{PP}}$ molar ratios (mean $\pm \mathrm{SE}: 17.8 \pm 3.5$, range: 6.6-63.3) and $\mathrm{DOC}_{\mathrm{PP}}$ : $\mathrm{Fe}_{\mathrm{PP}}$ ratios $(75.6 \pm 18.0,17.6-$ 168, Fig. A6), in agreement with previous studies (Heckman et al., 2018; Wagai et al., 2013). While C: metal ratios of synthesized organo-metal associations vary widely depending on experimental conditions, higher ratios indicate the dominance of organo-metal complexes over adsorptive association with metal oxides (Wagai and Mayer, 2007). In laboratory coprecipitation experiments, the $\mathrm{C}: \mathrm{Fe}$ molar ratio exceeding one led to organic encapsulation of Fe oxide particles (Kleber et al., 2015). Takahashi and Dahlgren (2016) estimated the $\mathrm{C}$ : metal molar ratio of 8.3 for organo-metal complexes in Andisols. We thus regard the PP-extractable phase as a mixture consisting largely of organo-metal complexes and their coprecipitates with varying amounts of alkali-soluble or desorbable $\mathrm{OM}$ and non-centrifugeable colloidal $\mathrm{Fe} / \mathrm{Al}$ oxide phases.

The OX-extractable metal phase is more likely influenced by short-range-order minerals (Parfitt and Childs, 1988; Rennert, 2019). We found strong positive correlation between $\mathrm{Al}_{\mathrm{OX}}$ and $\mathrm{Si}_{\mathrm{OX}}\left(r^{2}=0.76-0.99\right)$ with a relatively constant slope: the $\mathrm{Al}_{\mathrm{OX}}$ : $\mathrm{Si}$ OX molar ratio was 2.05 (allophanic Andisols), 2.25 (non-allophanic Andisols), 3.58 (Spodosols), and 3.91 (crystalline mineralogy group). Short-range-order aluminosilicates commonly found in Andisols and Spodosols have a molar ratio of 1-2 but possibly up to 4 for Al-rich allophane (Dahlgren et al., 1993). The OX-extractable phase in the studied soil fractions may also contain poorly crystalline gibbsite which can form rapidly in an OM-rich, acidic soil environment (e.g., Heckman et al., 2013). The source of $\mathrm{Al}_{\mathrm{OX}}$ and $\mathrm{Si}_{\mathrm{OX}}$ in the crystalline mineralogy group is less clear but likely to include interlayer components of $2: 1$ clay such as hydroxy Al polymers and aluminosilicates (Barnhisel and Bertsch, 1989; Wada and Kakuto, 1983) as well as amorphous gibbsite and silica (Drees et al., 1989). Most Fe phase is attributable to ferrihydrite and colloidal goethite for lower-density fractions and less-crystalline $\mathrm{Fe}$ oxides as well as magnetite - a primary mineral that associates little with OM due to the lack of hydroxylated surface - for higher-density fractions - for higher-density fractions (Cornell and Schwertmann, 2003; Parfitt and Childs, 1988; Rennert, 2019). The DC-extractable metal phase obtained after PP and OX extractions largely represents crystalline iron oxides and coprecipitated $\mathrm{Al}$ phases (Cornell and Schwertmann, 2003).

The sequential extraction results along the particle density gradient showed that greater proportions of total extractable $\mathrm{Fe}$ and $\mathrm{Al}$ were present as low-crystallinity phases (e.g., organic complexes, short-range-order minerals) in lowerdensity fractions (Fig. A4), which agrees well with the high affinity of these reactive phases to complex, coprecipitate, and adsorb OM (Kaiser and Guggenberger, 2003; Kleber et al., 2015; Wagai and Mayer, 2007; Wagai et al., 2013). $\mathrm{The} \mathrm{Al}: \mathrm{Fe}$ molar ratio of the extracts was relatively constant along the particle density gradient in some of the soils (Fig. A5), implying coprecipitation of the organo-Fe and organo-Al phases. The other soils, mostly in the Andisol and Spodosol groups, showed density-dependent patterns. Some of the allophanic Andisol samples, all of the non-allophanic Andisol samples, and one of the two Spodosol samples showed higher $\mathrm{Al}: \mathrm{Fe}$ ratios towards lower-density fractions, especially in the metal ${ }_{P P}$ and metalox phases (Fig. A5a-c). These higher $\mathrm{Al}: \mathrm{Fe}$ ratios may be explained by higher capability of $\mathrm{Al}$ ions to form an insoluble complex with organic ligands under low-pH and low metal: $\mathrm{C}$ ratio conditions (Nierop et al., 2002). In addition, the lower density of organo-Al coprecipitates $\left(1.7 \mathrm{~g} \mathrm{~cm}^{-3}\right)$ than that of organo-Fe ones $\left(2.5 \mathrm{~g} \mathrm{~cm}^{-3}\right.$, Kaiser and Guggenberger, 2007) may account for the observed higher $\mathrm{Al}: \mathrm{Fe}$ ratios. 

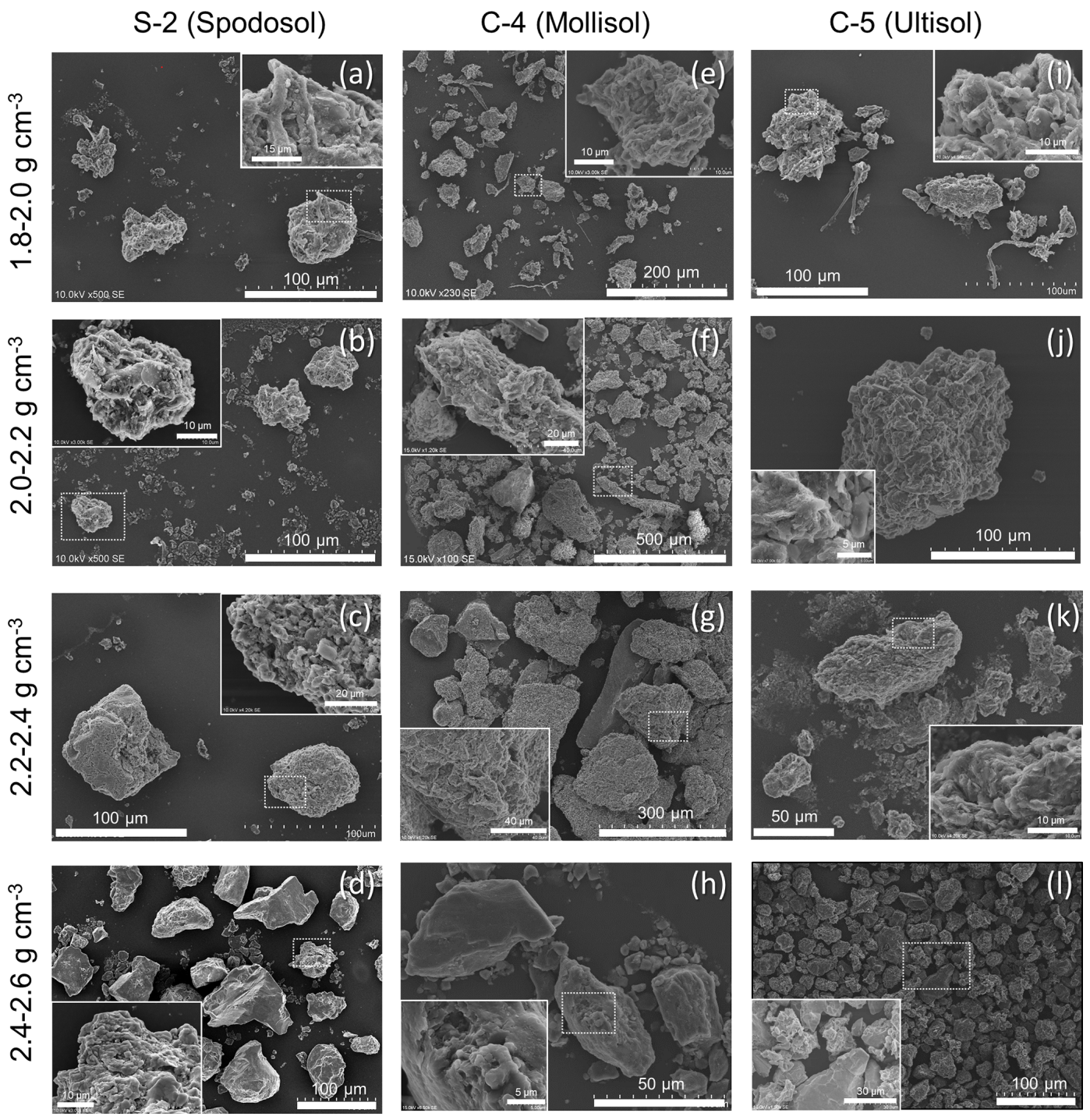

Figure 6. SEM images of three meso-density fractions and the adjacent higher-density fraction from S-2 soil (spodic horizon, a-d), C-4 soil (mollic horizon, e-h), and C-5 soil (kaolinitic A horizon, $\mathbf{i}-\mathbf{l}$ ). The enlarged view of the dotted rectangular section is shown at a corner, showing that the surface of selected particles was often aggregated or coated with finer materials such as clay platelets.

\subsection{Pedogenic metal enrichment at meso-density range}

The concentrations of extractable metal phases peaked at meso (intermediate) densities along the soil particle density gradient (Figs. 2, A1 left panels). Their dominance below the density cutoff of $2.4 \mathrm{~g} \mathrm{~cm}^{-3}$ is explained only by their association with OM, which has a much lower density $\left(\sim 1.4 \mathrm{~g} \mathrm{~cm}^{-3}\right)$, supporting our hypothesis. While the cutoff densities are somewhat arbitrary, we define the range between 1.8 and $2.4 \mathrm{~g} \mathrm{~cm}^{-3}$ as "meso density" for the following reasons: (i) a strong decline in $\mathrm{OM}$ concentration and $\mathrm{C}: \mathrm{N}$ ratio above $\sim 1.8 \mathrm{~g} \mathrm{~cm}^{-3}$ (Fig. A3a, b) suggests a major shift in OM source from plant detritus to microbially altered compounds as shown previously (e.g., Baisden et al., 2002), (ii) both the concentrations and distributions of the ex- tractable metals began to increase at $>1.8 \mathrm{~g} \mathrm{~cm}^{-3}$ (Fig. A1), and (iii) most soil minerals have density $>2.4 \mathrm{~g} \mathrm{~cm}^{-3}$ (see Introduction). Thus, the meso-density fractions are characterized by enrichment of pedogenic $\mathrm{Fe}$ and $\mathrm{Al}$ phases and their association with microbially altered OM. The extractable metal phases in the meso densities made up less than onefifth of soil masses, and the rest consisted largely of other minerals (e.g., crystalline clays) to form microaggregates resistant to mechanical shaking (Fig. 6). The meso-density enrichment of the metals thus implies their preferential association with $\mathrm{OM}$ relative to the other minerals.

Within the meso-density range, we found clear localization of different metal phases. The peak density of metalpP concentration had a median of $1.8(1.7-2.0) \mathrm{g} \mathrm{cm}^{-3}$, which was lower by $0.3-0.4 \mathrm{~g} \mathrm{~cm}^{-3}$ (on average) relative to 
metalox and metal $_{\mathrm{DC}}$ across the soils (Figs. 2, A1 left). This difference remained the same when assessing $\mathrm{Fe}$ and $\mathrm{Al}$ separately. The lower peak density of metalpP can result either from the inherent low density of this phase as indicated by the high C: metal ratios (see Sect. 4.1, Fig. 3a-c) or from its attachment to low-density particles. The latter implies that the metal density particles such as clay-covered POM (Fig. 6a, c), which would account for the presence of Fepp phase despite its higher density than the $\mathrm{Al}_{\mathrm{PP}}$ phase.

Progressive changes in the concentrations of both organic and inorganic (mineral) phases along the density gradient (Figs. 1, A3a) are depicted for an idealized soil (Fig. 7a). While distinguishing between plant-derived POM in lowdensity fraction and mineral-associated OM (MAOM) in high-density fraction within bulk soil is a critical first step (Lavallee et al., 2020; Sollins et al., 1999), the transition from POM to MAOM is rather continuous, and the latter contains a wide array of $\mathrm{OM}-$ mineral associations (Hatton et al., 2012; Jones and Singh, 2014; Sollins et al., 2009; Turchenek and Oades, 1979; Wagai et al., 2018), as conceptualized in the "soil continuum model" of soil OM formation (Lehmann and Kleber, 2015). The higher-density fractions (e.g., $>2.4 \mathrm{~g} \mathrm{~cm}^{-3}$ ) are increasingly dominated with primary minerals and Fe-bearing minerals, including crystalline $\mathrm{Fe}$ oxides (Jones and Singh, 2014; Sollins et al., 2009) with small amounts of N-rich OM (Fig. A3b). The lower-density fractions, on the other hand, hold increasing amounts of POM with appreciable levels of PP-extractable organo-metal phases, especially at around the $1.8 \mathrm{~g} \mathrm{~cm}^{-3}$ range (Figs. 1, $2)$. In the meso-density fractions $\left(1.8-2.4 \mathrm{~g} \mathrm{~cm}^{-3}\right)$, where the major portions of OM and extractable metals were located, significant portions ( $20 \%$ up to nearly $100 \%$ ) of the $\mathrm{OM}$ therein were co-dissolved by PP and OX extractions (Fig. 4). By applying a similar sequential extraction method to four soil profiles of contrasting mineralogy, Heckman et al. (2018) reported, on average, that $70 \%$ of total $\mathrm{C}$ was extractable. This extractable OM possibly existed in metalbound forms (Coward et al., 2017; Wagai et al., 2013; Zhao et al., 2016). The remaining, non-extractable $\mathrm{OM}$ in the meso-density fraction is presumably stabilized by mechanisms other than simple adsorptive association with the extractable metal phases.

\subsection{Organo-metal association, aggregation, and OM stabilization}

Organo-metal associations take place at multiple spatial scales within a bulk soil. Organo-metallic complexation, sorption, and coprecipitation occur at molecular to colloidal scales (Kleber et al., 2015). Current density fractionation results, on the other hand, suggest that the extractable metals and associated OM contribute to the formation of mesodensity aggregates with a few tens to hundreds of micrometers in diameter (Fig. 6). At the aggregate scale, organo- (a)

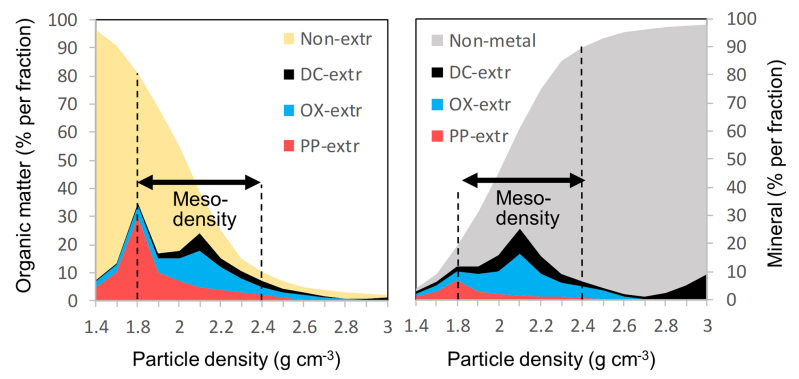

(b)
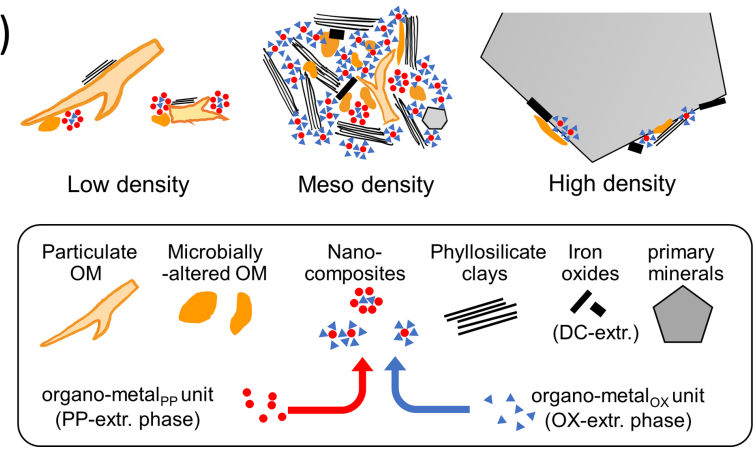

Figure 7. (a) Changes in the concentration of organic and mineral phases along soil particle gradient for an idealized soil. The concentrations of OM (left plot) and metals (right plot) extracted sequentially by pyrophosphate (PP), acid oxalate (OX), and dithionite (DC) per density fraction were shown in different colors. Nonextractable OM includes both particulate and microbially altered OM. Non-metal mineral phase includes phyllosilicate clays and primary minerals. (b) Schematic representation of low-, meso-, and high-density particles (upper) and their building blocks (lower). $\mathrm{PP}$ - and OX-extractable phases were presumed to be present as "nanocomposites" that act as glue to form meso-density microaggregates. The distribution of the nanocomposites across density fractions can explain the $\mathrm{C}$ : metal proportional relationship found in Figs. 3, A6, and A7. The nanocomposites rich in organo-metalPP unit are more abundant in OM-rich environments (e.g., lowerdensity fraction) relative to those rich in organo-metal $\mathrm{OX}$ units. Objects do not reflect the size difference among them.

mineral interactions occur with a much higher level of complexity (Keil and Mayer, 2014; Totsche et al., 2017). Here, we discuss how colloidal-scale interaction of metals and OM may be linked with micron-scale aggregate formation to account for the observed density-dependent patterns.

The observed proportionality between extractable metal phases and associated OM among the density fractions gives some hints to bridge between the colloidal and larger-scale associations. Significant C-metal correlations in PP- and OX-extractable phases, previously found across a range of bulk soils (Wagai et al., 2013), were shown among the density fractions (Fig. 3) and even within each soil in many cases (Figs. A6, A7). Specifically, positive DOC $\mathrm{PP}_{\mathrm{P}}$-metal ${ }_{\mathrm{PP}}$ correlation (largely $\mathrm{DOC}_{\mathrm{PP}}-\mathrm{Al}_{\mathrm{PP}}$ ) was found for all soils except for three samples from the crystalline mineralogy group (Fig. A6), while such a correlation for the subsequent 
OX extraction was limited to 8 out of the 14 Andisol samples (Fig. A7). Relatively constant $\mathrm{C}$ : metal ratios across the density fractions imply that the organo-metal association formed in the field remained intact as a physical unit during the fractionation steps, and these units were distributed among the fractions. These organo-metal units themselves are presumably present as colloid-sized "nanocomposites" (Fig. 7b) consisting of precipitated organo-metal complexes (i.e., metalpP phase) and, at least in the case of Andisols, OM-sorbed metal oxides (i.e., metalox phase), such as those identified in soils using high-resolution imaging techniques (Asano et al., 2018; Wen et al., 2014). Another feature is that these nanocomposites must be attached to larger particles containing some combination of low-density OM, highdensity mineral, or more of each other. Without sufficient size, Stokes' law predicts that they would have remained in density liquid and been lost during the centrifugation step.

We hypothesize that these organo-metal-rich nanocomposites function as a glue or effective binding agent (Asano et al., 2018) and promote ternary associations of OM, metal, and clays (Wagai and Mayer, 2007), as depicted in Fig. 7b. In fact, the meso-density materials were largely present as microaggregates with abundant clays on their surfaces (Fig. 6). For the two soil samples (A-3, C-4) that we further sizefractionated following the density fractionation, 59\%-84\% of the mass in the meso-density fractions consisted of $<2 \mu \mathrm{m}$ sized particles (isolated after maximum dispersion by sonication) that were enriched in the extractable metals relative to bulk samples (unpublished data), in support of our hypothesis. How do these nanocomposites form and function? The $\mathrm{Al}$ and $\mathrm{Fe}$ are trivalent metals and can act as (monomeric or polynuclear) glue between different organic ligands, particles, and surfaces. An organic particle or coating may stick to a mineral surface via van der Waals interactions but become aggregated to other organic particles via a polyvalent metal connection. Furthermore, monomeric $\mathrm{Fe}$ and $\mathrm{Al}$ can form various ternary complexes in the presence of $\mathrm{OM}$ and other dissolved inorganic species found in soil solution such as $\mathrm{Ca}$ and $\mathrm{Si}$, thereby preventing their polymerization (Adhikari et al., 2019; Tamrat et al., 2019; Yang et al., 2017). These organo-metal-rich mixed-phase nanocomposites, acting as glues (organo-metallic glue hypothesis), can give a mechanistic explanation for the moderately strong $\mathrm{C}-$ metal correlations among the density fractions (Figs. 3, A6, A7) as well as for the dominance of OM, metal, and presumably clay in the meso-density range (Figs. 5, A1 right panels).

Such micro-scale aggregation can enhance OM stability by reducing the accessibility of microbes, exo-enzymes, and/or e-acceptors (Balesdent et al., 2000; Keil and Mayer, 2014; Lehmann et al., 2007; Sollins et al., 1996). Among the pedogenic metal phases, crystalline Fe oxides (roughly corresponds to the metal $\mathrm{DC}$ phase) strongly enhance microaggregation, particularly in highly weathered soils (e.g., Shang and Tiessen, 1998). This metal phase can protect relatively small amounts of OM for a prolonged time (e.g., Eusterhues et al., 2003; Mikutta et al., 2006). Short-range-order mineral could also contribute to aggregation and thus physical protection of OM within such a mineral matrix. Microaggregates in Andisols (especially metalox-rich ones) show high physical stability (Shoji et al., 1993) even against wet oxidation and reductive dissolution treatments (Churchman and Tate, 1986). Stable ternary associations of OM, lowcrystallinity $\mathrm{Fe}$ oxide, and microporous allophane in an Andisol has been hypothesized (Filimonova et al., 2016). A portion of soil Fe phase such as low-crystallinity Fe oxyhydroxide, and presumably associated OM, can survive harsh dithionite extraction (Coward et al., 2018), in some cases due to the protective effect of metalox phases. Even after strong dispersion by sonication (up to $1500 \mathrm{~J} \mathrm{~mL}^{-1}$ ), $60 \%-$ $70 \%$ of total $\mathrm{C}$ and extractable metals in Andisols remained in the meso-density fractions (Basile-Doelsch et al., 2007; Wagai et al., 2015) that were largely present as micron- and submicron-sized aggregates (Asano and Wagai, 2014; Asano et al., 2018). Similarly, the main C storage location in tropical Ferrasols was sonication-resistant particles that were characterized by slightly higher density $\left(2.45-2.8 \mathrm{~g} \mathrm{~cm}^{-3}\right)$, enrichment of halloysite, and resistance to $\sim 200$ years of cultivation (Basile-Doelsch et al., 2009). Compared to these metal oxide phases, organo-metal complexes are more labile, for instance, with a change in $\mathrm{pH}$ (Takahashi and Dahlgren, 2016). Thus their contribution to aggregation may be lower, although this phase can be physically occluded within stable microaggregates. Faster turnover (more ${ }^{14} \mathrm{C}$ enrichment) of PP-extractable $\mathrm{C}$ compared to the $\mathrm{C}$ associated with other mineral phases (Heckman et al., 2018) as well as the metal ${ }_{P P}$ enrichment at lower density (Figs. 1,2) support this view. While the relative importance of specific metal phases remains to be elucidated, these extractable metals likely contribute to $\mathrm{OM}$ stabilization by promoting aggregation via organo-metallic glues as well as by direct organo-metal interaction via complexation and adsorption.

\subsection{Co-localization of metal and microbially altered OM at meso-density fraction}

We further considered the distributions of metal and OM along the density gradient to translate the observed results into field-level processes. Their distributions are determined by two variables: mass distribution and the concentration of the respective elements. The peak density of mass distribution was quite variable among the studied soils (Fig. 5), which will be further examined in our companion study (Kajiura et al., 2020). Consequently, the peak densities of metal phases were also moderately variable. The mean peak densities of both $\mathrm{C}$ and all metal phases were, however, $\sim 2.1 \mathrm{~g} \mathrm{~cm}^{-3}$ (Fig. 5). In fact, the meso-density range $\left(1.8-2.4 \mathrm{~g} \mathrm{~cm}^{-3}\right)$ accounted for $59 \pm 14 \%$ and $64 \pm 15 \%$ (mean $\pm \mathrm{SD}$ ) of total $\mathrm{C}$ and $\mathrm{N}$, respectively, among the studied soils. Similarly, more than half of the total extractable metals were in the meso-density range $\left(65 \pm 17 \%\right.$ of $\mathrm{Fe}_{\mathrm{PP}}$, 
$63 \pm 15 \%$ of $\mathrm{Al}_{\mathrm{PP}}, 56 \pm 14 \%$ of $\mathrm{Fe}_{\mathrm{OX}}, 70 \pm 13 \%$ of $\mathrm{Al}_{\mathrm{OX}}$, $61 \pm 17 \%$ of $\mathrm{Fe}_{\mathrm{DC}}$, and $66 \pm 15 \%$ of $\mathrm{Al}_{\mathrm{DC}}$ ). The meso-density co-localization of $\mathrm{OM}$ and the extractable metals found here thus suggest that metal binding via multiple physicochemical processes discussed above contributes to the stability of pedogenic metal phases against leaching/dissolution and that of OM against biological degradation. Our view is consistent with $\mathrm{C}$ and $\mathrm{N}$ isotope tracer studies that identified mesodensity fractions as the main reservoir of stabilized $\mathrm{C}$ across a wide range of soils (Baisden et al., 2002; Crow et al., 2014; Hatton et al., 2012; Sollins et al., 2009; Wagai et al., 2018; Jones and Singh, 2014) with an exception of Fe-rich weathered soils where $>2.4 \mathrm{~g} \mathrm{~cm}^{-3}$ fractions store more $\mathrm{C}$ due to the abundance of heavy minerals (Jones and Singh, 2014; Sollins et al., 2009).

The co-localization of $\mathrm{OM}$ and metals is illustrated for the three forest soils developed through contrasting pedogenesis (Fig. 8). In the tropical Ultisol, the DC-extractable phase accounted for greater proportions of total extractable metal than the other two soils (Fig. 8a). Accordingly, this phase explained the majority of the OM extractable by PP, OX, and DC (Wagai et al., 2013). The spodic horizon sample under cooler climate stored more $\mathrm{C}$ in lower-density fractions and held major portions of metals as PP-extractable phase (Fig. 8b), in agreement with the podzolization concept (Lundström et al., 2000). The allophanic Andisol held much higher amounts of extractable metals and $\mathrm{C}$ than the other two soils (Fig. 8c). Co-localization at a narrower density range in the Andisol can be attributable to higher contents of organo-metallic glue.

\subsection{Implications}

The similar distributions of $\mathrm{OM}$ and extractable $\mathrm{Fe}$ and $\mathrm{Al}$ found here (Figs. 5, 8, A1) imply a common set of processes that promote the formation of organo-metal associations across a range of pedogenic environments. Almost all samples showed a unimodal distribution with the peaks in the meso-density range (Figs. 1, 2, and A1). The three processes operating at a fundamental level are (1) the production of microbially altered OM from the original low-density plant detritus, (2) the release of metals from high-density, weatherable minerals, and (3) the formation of organo-metal-rich nanocomposites and concurrent incorporation of low- and high-density materials (most importantly, clays) into meso density via their gluing properties - the organo-metallic glue hypothesis (Fig. 8).

From the organic side, the most consistent change along the particle density gradient was the progressive decline in $\mathrm{C}: \mathrm{N}$ ratio and $\mathrm{OM}$ concentration from low- to highdensity fractions (Fig. A3), which is generally explained by the shift from POM to microbially processed compounds (Baisden et al., 2002; Gunina and Kuzyakov, 2014). Microbially driven, oxidative depolymerization increases the solubility, the number of ionized functional groups (especially

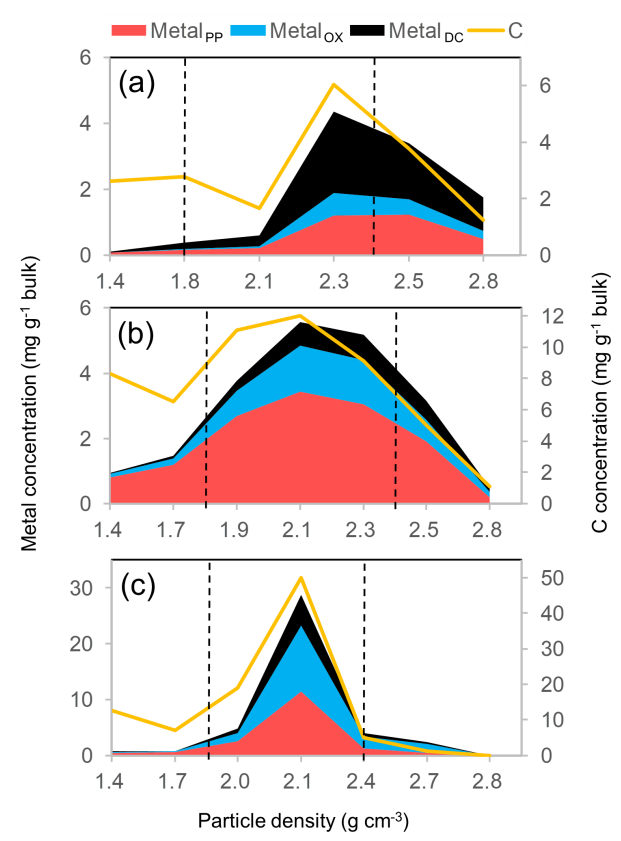

Figure 8. The distribution of the extractable metal phases $(\mathrm{Al}+0.5 \mathrm{Fe})$ on the left $y$ axis and that of $\mathrm{C}$ on the right $y$ axis along the density gradient for three undisturbed forest soils. A kaolinitic Ultisol (O-5 in Table 1) developed from sedimentary rock under tropical wet climate (a), a Spodosol Bhs horizon (S-2) with quartz and plagioclase-rich mineralogy from glacial till under cool temperate moist climate (b), and an allophanic Andisol (A-10) from tephra under warm temperate moist climate (c). Vertical dotted lines show the meso-density range.

carboxylic groups), and acidity thereby enhancing the reactivity of remaining OM with metals and mineral surfaces (Heckman et al., 2013; Kleber et al., 2015). The accumulation of the pedogenic metal phases from low to mesodensity fractions (Figs. 2, A1) thus suggests that oxidative depolymerization of POM appears to be necessary for the organo-metal associations. From the mineral side, metals released by weathering can readily bind to organic ligands. For instance, negatively charged bacterial cell surface attracts metal cations, which leads to the nucleation and precipitation of low-crystallinity $\mathrm{Fe}$ oxyhydroxides and aluminosilicates (Ferris et al., 1989; Urrutia and Beveridge, 1994). Tamrat et al. (2019) showed nano-sized Fe-Al-Si coprecipitate formation from biotite weathering solution in the presence of lowmolecular organic acid (termed nanosized coprecipitates of inorganic oligomers with organics, "nanoCLICs"). These reactions likely promote the formation of the nanocomposites having a relatively narrow range of $\mathrm{OM}$ : metal ratios that can act as relatively persistent glue to bind soil particles, most importantly phyllosilicate clays that themselves strongly bind with $\mathrm{OM}$

The three processes identified (Fig. 9) are ultimately driven by the factors driving pedogenesis - physicochemical forces (heat, water, acidity) and biological activity. Then 


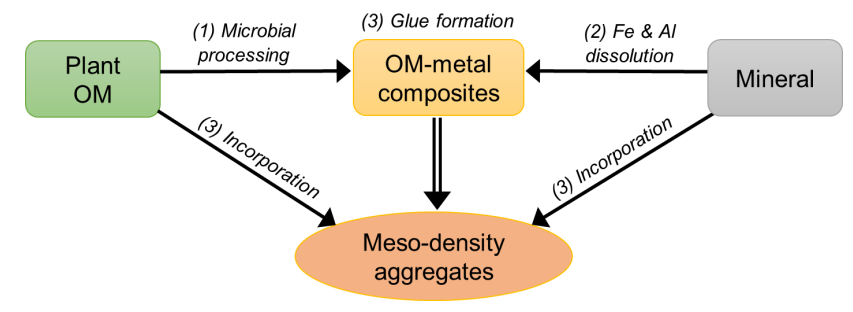

Figure 9. Conceptual illustration of meso-density aggregate formation. The three main processes are (1) microbial processing of plant-derived organic matter, (2) metal dissolution via chemical weathering, and (3) the formation of organo-metallic glue, which promote meso-density microaggregate formation by incorporating some POM and mineral.

the environmental conditions promoting the three processes in balance would lead to local maxima of the organo-metallic glue and meso-density aggregates (see Fig. A8 and the discussion therein). Such condition at the global scale includes acidic soils under wetter climate (Rasmussen et al., 2018) especially with the parent materials that are abundant in weatherable minerals. At the pedon scale, the interface of $\mathrm{O} / \mathrm{A}$ horizons or the $\mathrm{B}$ horizons that experience podzolization would fit with this condition. At smaller scales, micro spots having redox fluctuation and rhizosphere likely promote the organo-metallic glue formation due to the abundance of organic ligands and active dissolution/precipitation of $\mathrm{Fe}$ and other mineral phases (Chen et al., 2020; Garcia Arredondo et al., 2019; Keiluweit et al., 2015; Yu, 2018). The current view and the growing evidence on rapid formation of various organo-metal-mineral associations at submicron scale (e.g., Basile-Doelsch et al., 2015; Garcia Arredondo et al., 2019; Heckman et al., 2013) suggest that the concept of soil C saturation and soil's capacity to protect $\mathrm{C}$ based on clay and silt contents (e.g., Six et al., 2002) require refinement.

Our results and proposed hypothesis may help to integrate some of the important findings and concepts in the literature. The predominance of stabilized OM in organo-mineral fractions (e.g., $<20 \mu \mathrm{m}$ size class or meso-density range) has been shown by physical fractionation studies (e.g., Christensen, 2001; Six et al., 2000; von Lützow et al., 2007), but the involvement of pedogenic metal phases was much less studied. Protective effects of phyllosilicate clays (e.g., Barré et al., 2014) and pedogenic metal phases (e.g., Porras et al., 2017; Wagai and Mayer, 2007) on OM are likely to occur concurrently, and possibly synergistically, within mesodensity microaggregates. Enrichment of certain clay minerals in meso-density fractions (e.g., smectite in a Vertisol, kaolinite in Spodosol and Oxisol, Jones and Singh, 2014) and enhanced physical stability of clay aggregates by goethite particle incorporation (Dultz et al., 2019) support this idea. The aggregate hierarchy concept recognized the role of lowcrystallinity mineral phases and microbial compounds as persistent binding agents (Tisdall and Oades, 1982) but not their interaction or formation pathways. With new analytical techniques and methodologies, our understanding of microaggregate formation (e.g., Asano and Wagai, 2014; Lehmann et al., 2007; Totsche et al., 2017) and molecular-scale interaction of OM, metals, and other inorganic phases (e.g., Chen et al., 2020; Tamrat et al., 2019) is advancing. We believe that a remaining key question is how these molecular-scale interactions are related to soil physical fractions and the formation of a hierarchical aggregate structure. The current study provides some insights to this end. Further efforts to fill the scale gap will be important to better understand soil's protective capacity to store $\mathrm{OM}$ and for the development of more mechanistic biogeochemical models. 
Appendix A

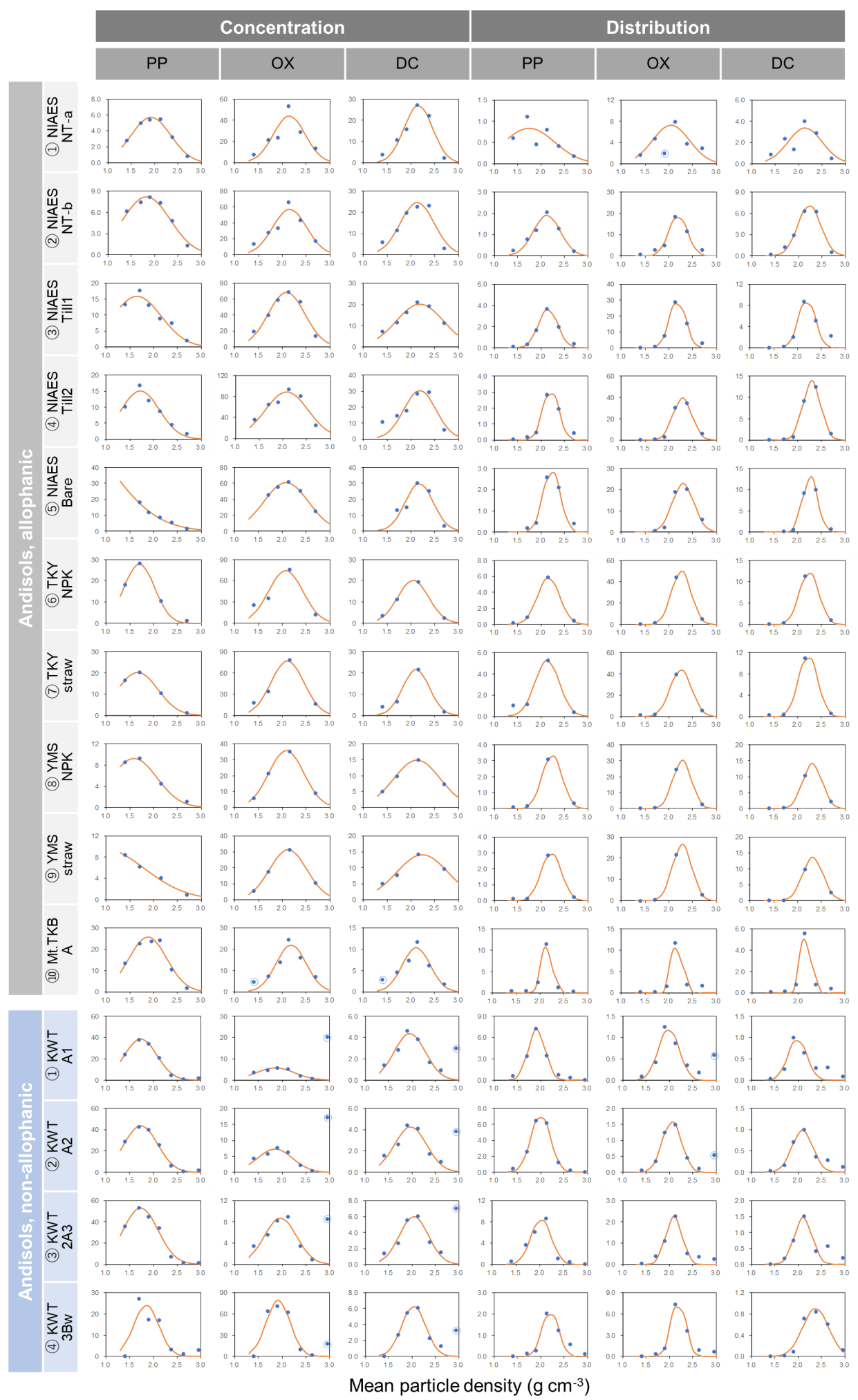

Figure A1. 


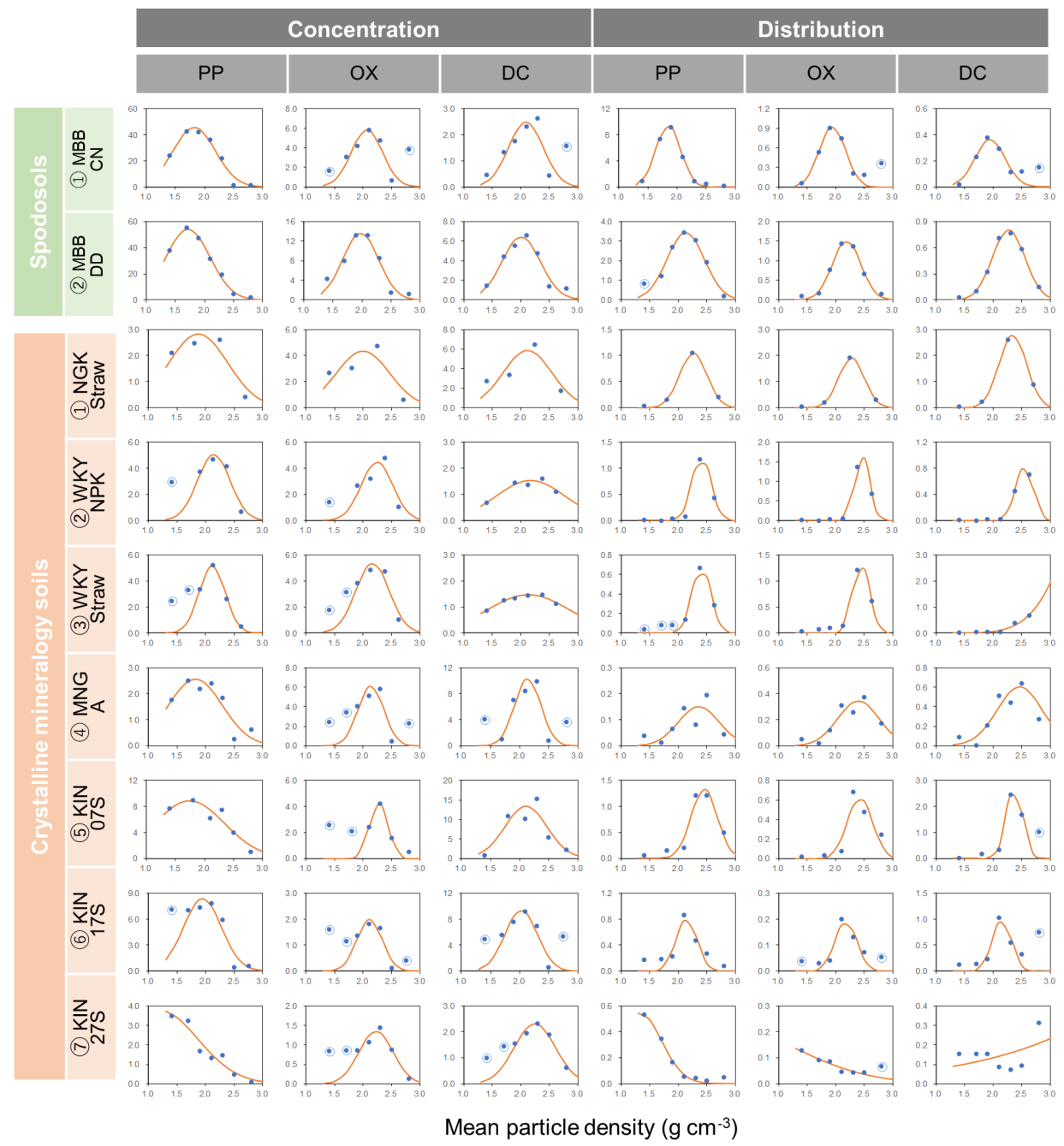

Figure A1. Extractable metal $(\mathrm{Al}+0.5 \mathrm{Fe})$ against mean particle density for each soil sample. The metal concentrations (mg $\left.\mathrm{g}^{-1} \mathrm{fraction}\right)$ from pyrophosphate (PP), acid oxalate (OX), and dithionite-citrate (DC) extractions are shown in the left three panels. The distributions of $\mathrm{PP}, \mathrm{OX}$, and DC-extractable metal phases $\left(\mathrm{mg} \mathrm{g}^{-1}\right.$ whole soil) are in the right three panels. Normal distribution curve fit is shown as line. The data points circled in blue were omitted from the fitting. 


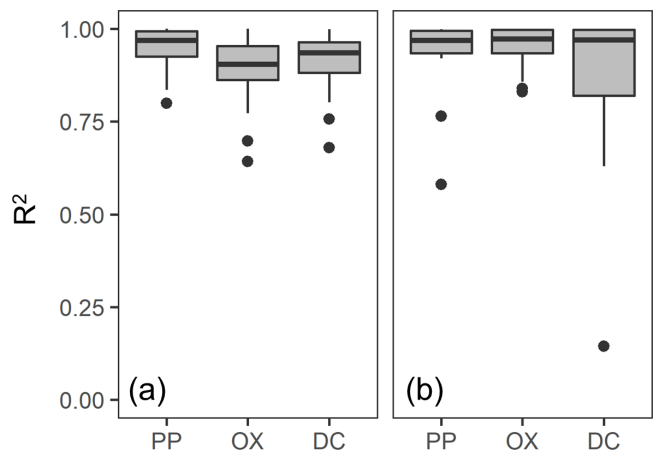

Figure A2. Boxplot of $r^{2}$ value for the normal distribution curve fitting of the extractable metal concentration (a) and distribution (b) against mean particle density. The fitting was done for each soil and each extraction as shown in Fig. A1.
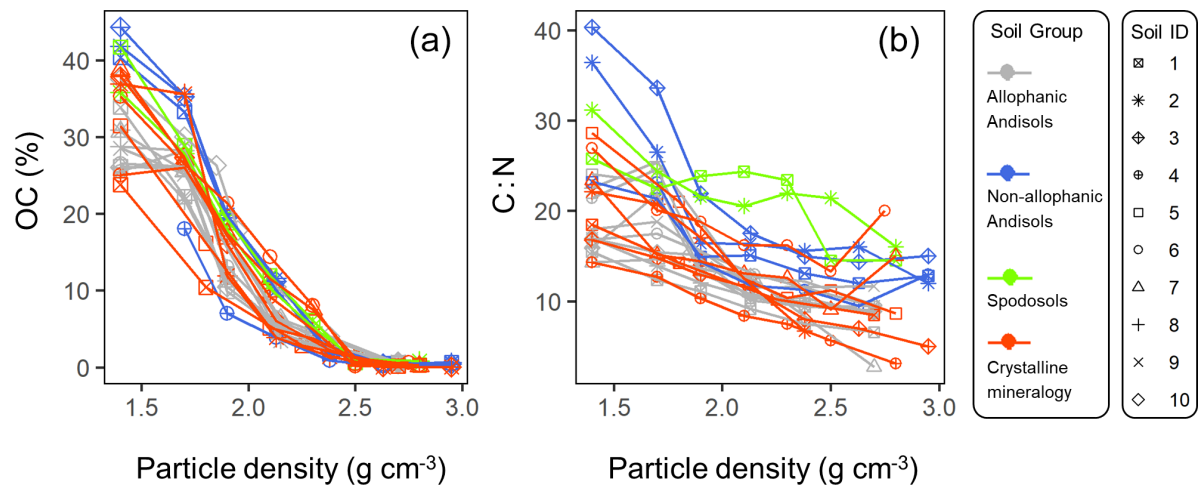

Figure A3. Line graphs showing organic $\mathrm{C}$ concentration per fraction, as weight $\%$ (a) and $\mathrm{C}: \mathrm{N}$ ratio (b) against soil particle density. Each line represents each soil sample which belongs to one of the four soil groups. Soil ID numbers, shown in different symbol shapes, correspond to Table 1 .
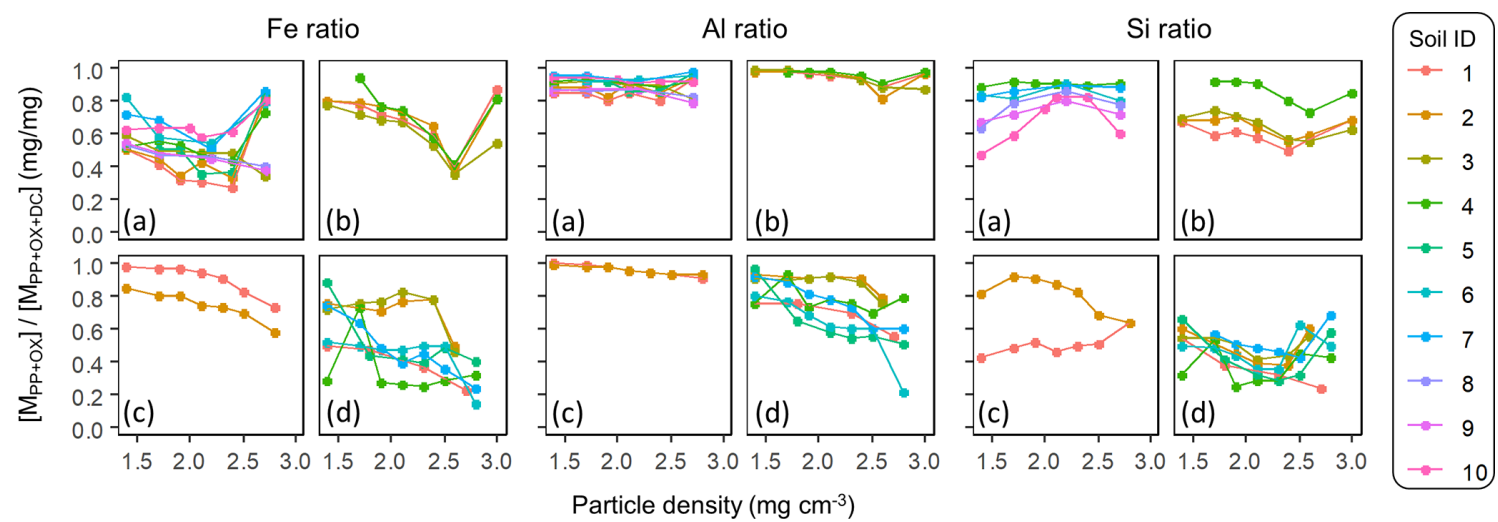

Figure A4. Proportion of total extractable Fe (left), Al (center), and Si (right panels) present as pyrophosphate- plus oxalate-extractable phases. This ratio obtained from each density fraction was shown along the density gradient for allophanic Andisols (a), non-allophanic Andisols (b), Spodosols (c), and crystalline mineralogy group (d). Each symbol represents the individual soil sample ID in Table 1. 

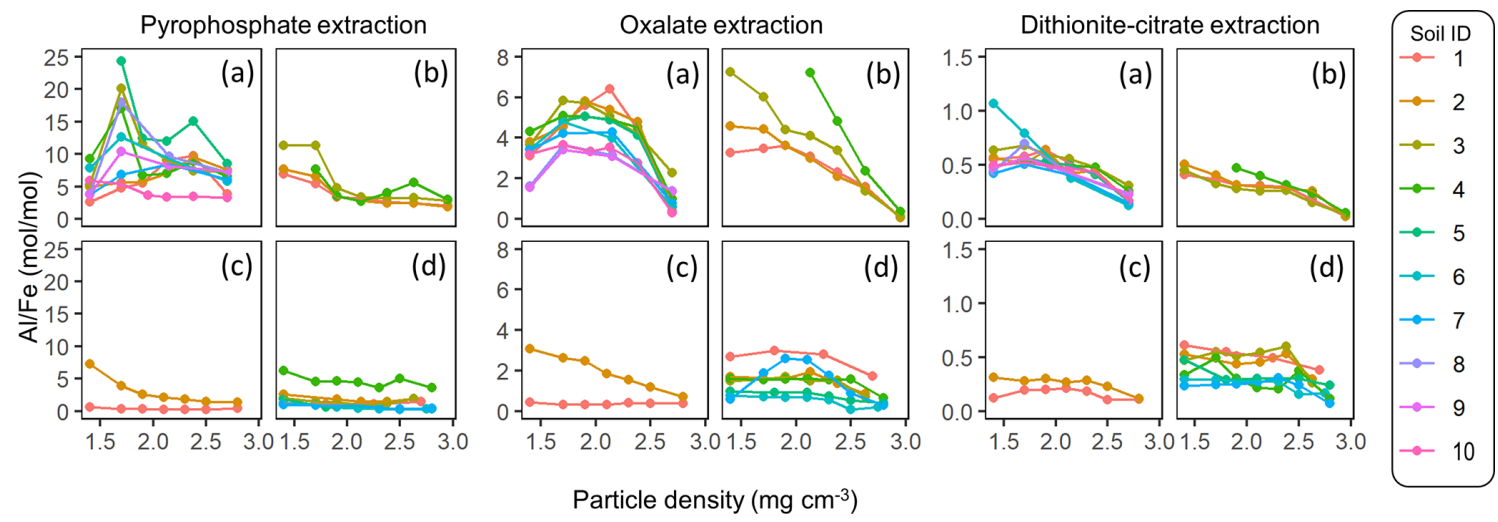

Figure A5. Molar Al-to-Fe ratio of each extractable phase from each density fraction along the density gradient. The ratio was shown for initial pyrophosphate (left four plots) and subsequent acid oxalate (middle four plots), and final dithionite-citrate extractions (right four plots) were shown for allophanic Andisols (a), non-allophanic Andisols (b), Spodosols (c), and crystalline mineralogy group (d). Each symbol represents the individual soil sample ID in Table 1.

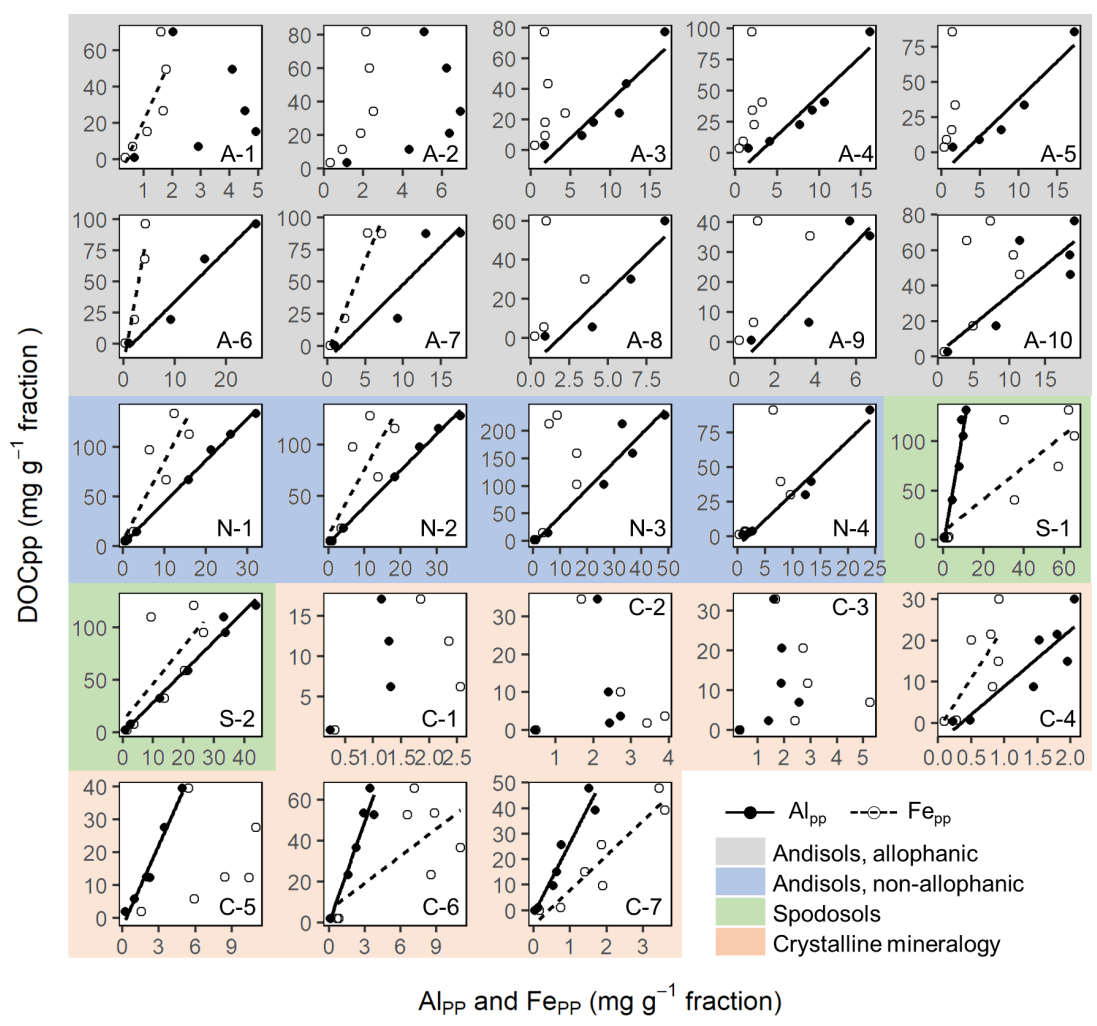

Figure A6. Scattered plots of pyrophosphate-extractable Fe and Al against dissolved organic C concentration for each soil sample. Soil sample ID in each plot corresponds to that from Table 1. Solid lines represent significant linear regressions at $p<0.1$. 


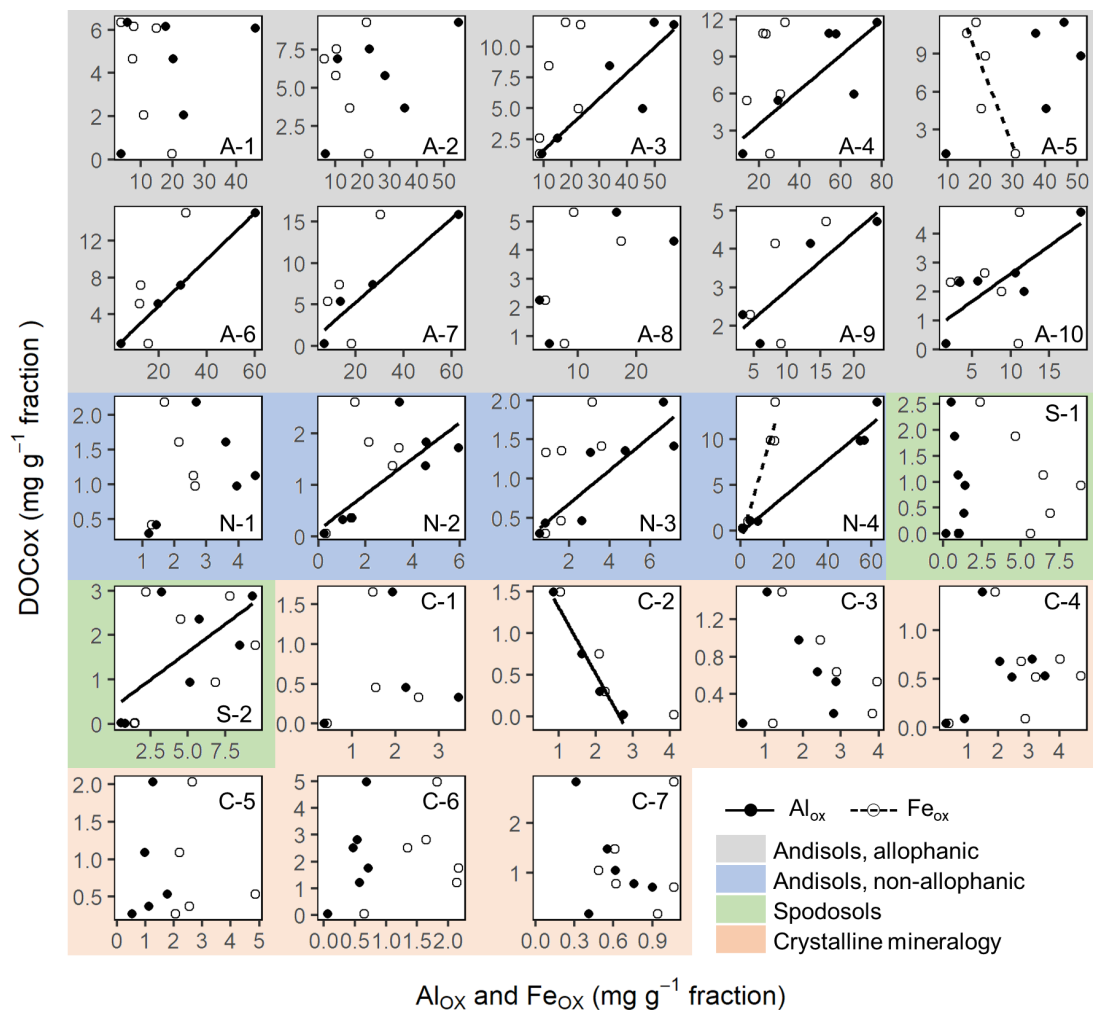

Figure A7. Scattered plots of acid-oxalate-extractable Fe and Al against dissolved organic C concentration for each soil sample. Soil sample ID in each plot corresponds to that from Table 1. Solid lines represent significant linear regressions at $p<0.1$.

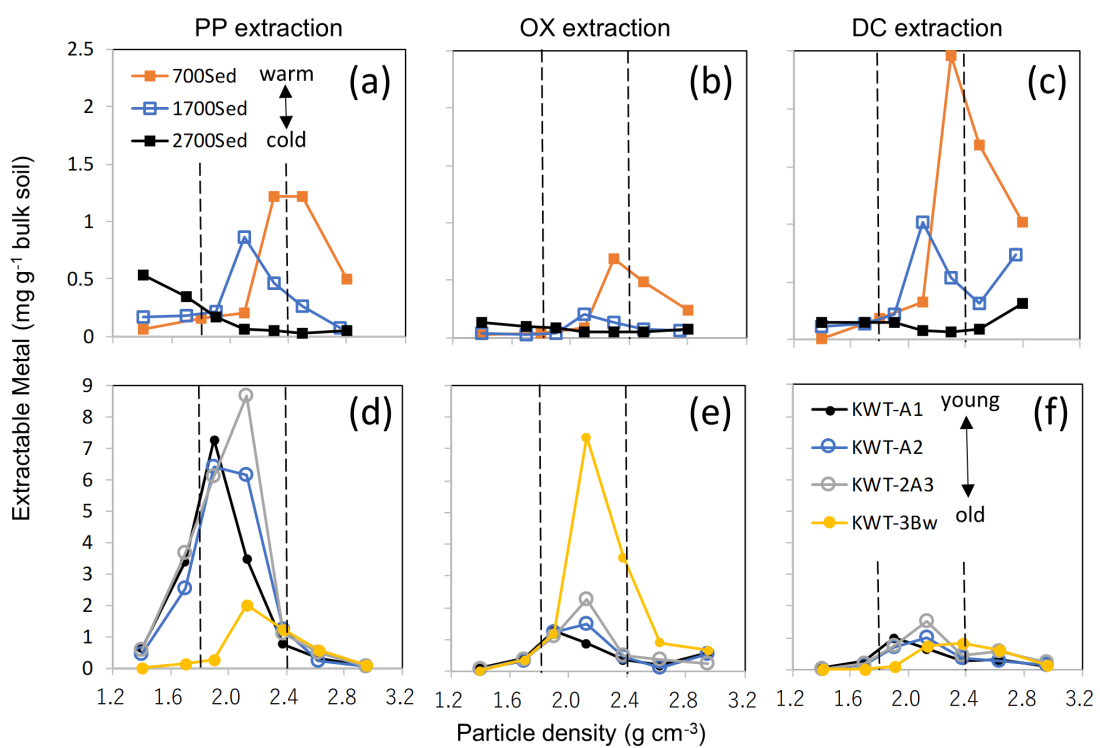

Figure A8. The distribution of the extractable metal phases $(\mathrm{Al}+0.5 \mathrm{Fe})$ along the particle density gradient for two soil series. The upper three plots show PP- (a), OX- (b), and DC-extractable metals (c) for three A horizon soils under tropical forest along an elevation gradient from a weathered soil under warm climate at $700 \mathrm{~m}$ (sample ID: C5), moderately weathered soil at $1700 \mathrm{~m}$ (C6), and much less weathered soil at $2700 \mathrm{~m}$ (C7). The lower panels (d, e, f) showed surface and buried horizons of a non-allophanic Andisol profile (sample ID: N1-N4) that received multiple tephra deposits. Shaded zones show the meso-density range. 


\section{Discussion associated with Fig. A8}

The relative balance of the three processes (OM supply and microbial processing, metal dissolution via weathering, and their binding/aggregation, Fig. 9) appear to control the nature of meso-density metal enrichment. Environmental gradients (e.g., climo- and chrono-sequences) give clear shifts in the balance of the three. Along a strong temperature gradient on a forested mountain slope, surface soils at higher altitudes experience slower rates of OM decay (and thus higher OM accumulation) and mineral weathering than those at warmer lower-altitude soils. The majority of pedogenic metals in the $2700 \mathrm{~m}$ soil altitude (C-5) was present as PP-extractable phase and their distribution peaked at $<2.0 \mathrm{~g} \mathrm{~cm}^{-3}$ fractions, whereas the $700 \mathrm{~m}$ altitude soil (C-7) held the metals mostly as DC- and PP-extractable phases that were mainly present at $>2.2 \mathrm{~g} \mathrm{~cm}^{-3}$, and the mid-altitude soil (C-6) showed the patterns in between them (Fig. A8a-c). Meso-density metal enrichment was strongest in the $700 \mathrm{~m}$ soil. This result can be explained by (1) higher microbial processing of $\mathrm{OM}$ as the forest productivity, and thus OM supply to soil was the highest (Kitayama and Aiba, 2002; Wagai et al., 2008), and (2) higher degree of weathering under the warm moist climate regime (Wagai et al., 2009).

Along with a volcanic soil profile experiencing upbuilding pedogenesis, we also observed the decline in metal $_{P P}$ and a concurrent increase in metalox over pedogenic time (from upper to lower horizons), implying a shift in the dominant metal phase from organo-metal complexes to short-range-order mineral. Concurrently, we found the increase in metal distribution from low towards higher density (Fig. A8d-f). The top three horizons (A1, A2, and 2A3) were developed over the last ca. $10 \mathrm{kyr}$ based on key tephra (Hijiori pumice) identified between the 2A3 and 3Bw horizons, suggesting that the organo-metallic glue enriched in the PP-extractable phase was replaced by that rich in the OXextractable phase over ca. $10 \mathrm{kyr}$ under a reduced $\mathrm{OM}$ input (buried) condition.
These results therefore suggest general patterns in the localization of specific metal phases and the mode of OMmetal association across scales as follows: (i) $\mathrm{Al}$ and $\mathrm{Fe}$ released by weathering preferentially bind to organic ligands to form an organo-metallic complex in OM-rich environment (e.g., surface horizon especially under cooler climate) and (ii), under the pedogenic condition where net organic supply to mineral surface is limited for a prolonged time (e.g., rapid decomposition under a warm, wet condition and deeper horizons), polymerization of $\mathrm{Fe}$ and $\mathrm{Al}$ (and $\mathrm{Si}$ ) is facilitated. The latter leads to the formation of shortrange-order mineral which is further transformed to wellcrystalline oxides over time. In other words, pedogenic reactions such as dynamics of mobile weathering products and secondary mineral formation occurring at a pedon scale (e.g., the depth-dependent framework, Lawrence et al., 2015) can be observed within bulk soils by the current approach combining sequential density fractionation with the extraction of operationally defined metal phases. 


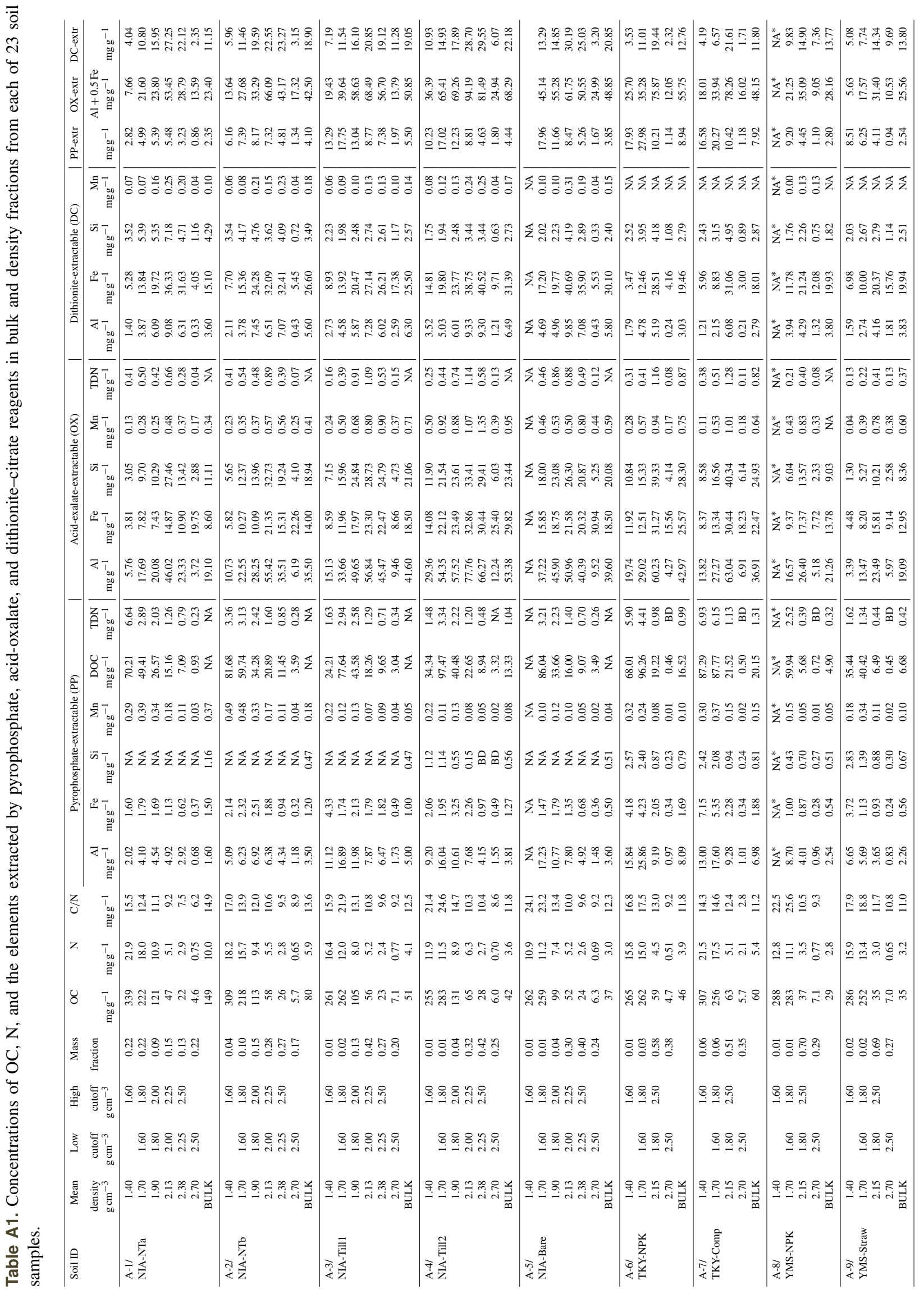




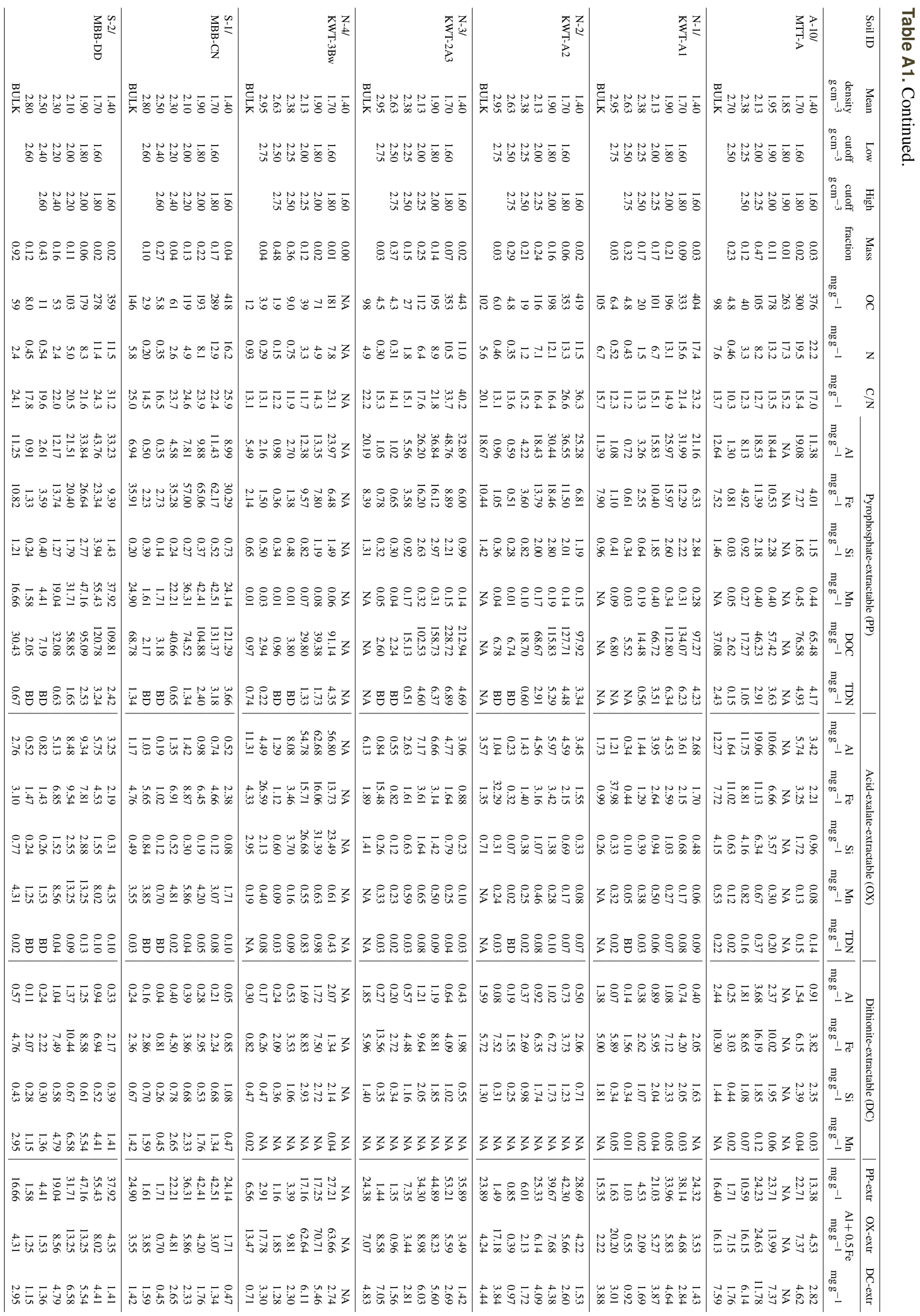




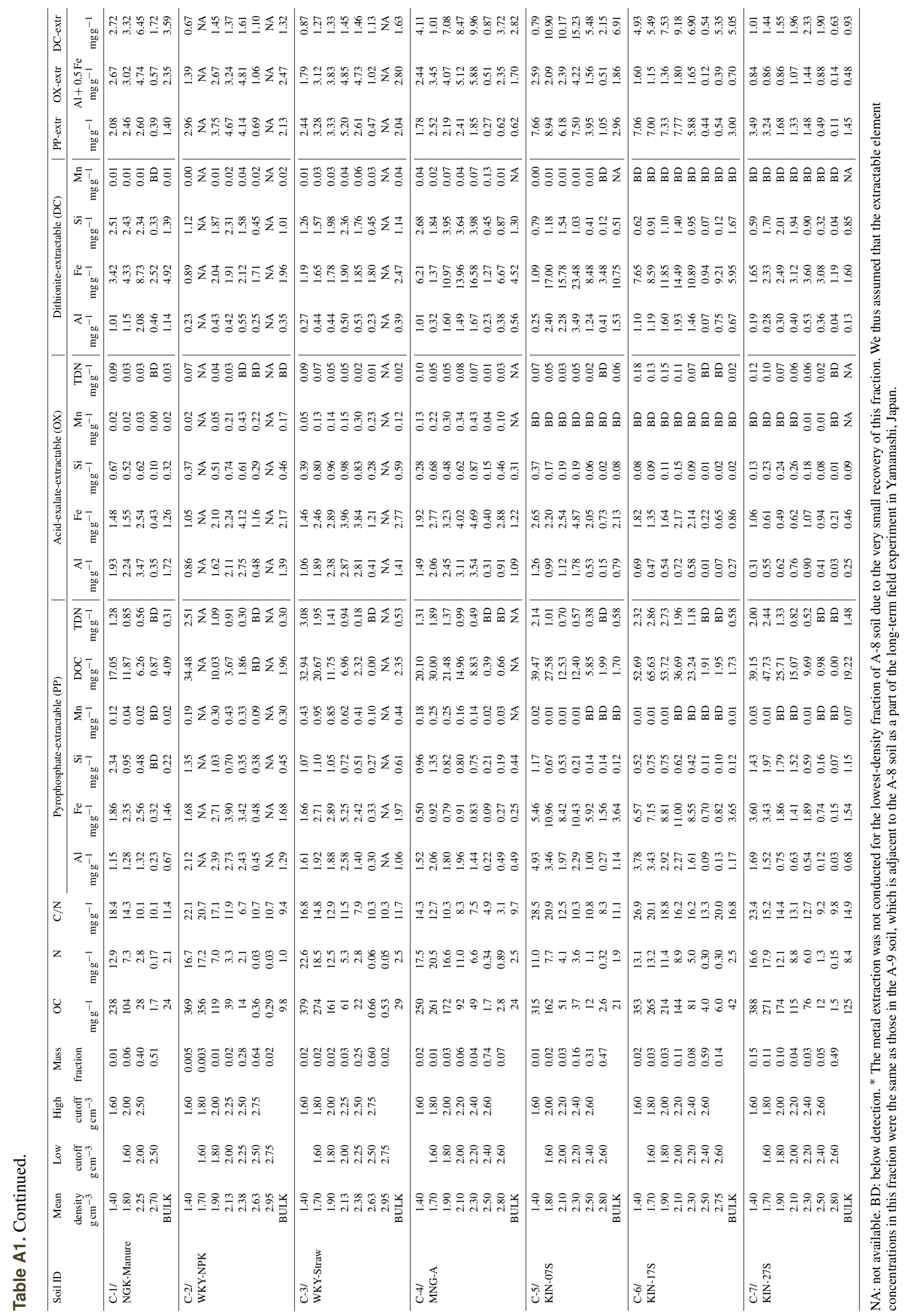


Table A2. The results of a cubic polynomial regression model applied to each of the four soil groups for pyrophosphate-extractable organic $\mathrm{C}\left(\mathrm{DOC}_{\mathrm{PP}}\right)$ and the sum of pyrophosphate- and oxalate-extractable $\mathrm{C}\left(\mathrm{DOC}_{\mathrm{PP}}+\mathrm{DOC}_{\mathrm{OX}}\right)$.

\begin{tabular}{lrrrr}
\hline & $\begin{array}{r}\text { Allophanic } \\
\text { Andisol }\end{array}$ & $\begin{array}{r}\text { Non-allophanic } \\
\text { Andisol }\end{array}$ & Spodic & $\begin{array}{r}\text { Crystalline } \\
\text { mineralogy }\end{array}$ \\
\hline DOC & & & & \\
\hline$r^{2}$ & 0.17 & 0.41 & 0.55 & 0.50 \\
RMSE & 0.12 & 0.24 & 0.12 & 0.11 \\
$n$ & 49 & 27 & 14 & 39 \\
$F$ & 3.13 & 5.21 & 4.05 & 11.86 \\
$p$ & 0.0347 & 0.0068 & 0.040 & $<0.0001$ \\
\hline DOC & & & & \\
\hline$r^{2}$ & 0.32 & 0.47 & 0.55 & 0.51 \\
RMSE & 0.12 & 0.22 & 0.12 & 0.11 \\
$n$ & 49 & 27 & 14 & 39 \\
$F$ & 6.99 & 6.73 & 4.12 & 12.27 \\
$p$ & 0.0006 & 0.0020 & 0.0384 & $<0.0001$ \\
\hline
\end{tabular}


Data availability. The data used in this study are available from the corresponding author upon reasonable request.

Author contributions. RW designed the experiments that were carried out by all the co-authors. KM developed the mathematical approach to assess the density-dependent metal distribution. RW prepared the manuscript with contributions from all the co-authors.

Competing interests. The authors declare that they have no conflict of interest.

Acknowledgements. We gratefully thank Rie Matsuura (Tokyo Metropolitan Agriculture and Forestry Research Center), $\mathrm{Ku}-$ nio Maruoka (Saitama Agricultural Technology Research Center), Shuhei Yamazaki (Yamanashi Prefectural Agricultural Technology Center), Hideyuki Wakasawa (Shizuoka Prefectural Research Institute of Agriculture and Forestry), Masahiro Kasuya (Agritechnology Center), and Yasuhiro Hayashi (Wakayama Research Center of Agriculture, Forestry and Fisheries) for kindly sharing soils from their long-term experimental fields. We also thank Ivan J. Fernandez and Tsutomu Ohno (Univ. of Maine), Syuntaro Hiradate (Univ. of Kyushu), Toko Tanikawa (Univ. of Nagoya), Kanehiro Kitayama (Univ. of Kyoto), and the Sabah Park for field support and Yasuko Yaegaki and Chie Hayakawa for laboratory assistance. Comments by Lawrence M. Mayer on an earlier draft are greatly thanked.

Financial support. This research has been supported by the JSPS (Japan Society for the Promotion of Science) (grant nos. 15KK0028, 15H02810, 15KT0036, 18K05369, and MAFFJPJ008837, Japan).

Review statement. This paper was edited by Cornelia Rumpel and reviewed by two anonymous referees.

\section{References}

Adhikari, D., Sowers, T., Stuckey, J. W., Wang, X., Sparks, D. L., and Yang, Y.: Formation and redox reactivity of ferrihydriteorganic carbon-calcium co-precipitates, Geochim. Cosmochim. Ac., 244, 86-98, https://doi.org/10.1016/j.gca.2018.09.026, 2019.

Anthony, J. W., Bideaux, R. A., Bladh, K. W., and Nichols, M. C.: Volume III. Halides, Hydroxides, Oxides, Handbook of Mineralogy, Mineralogical Society of America, Chantilly, VA 201511110, USA, 1997.

Asano, M. and Wagai, R.: Evidence of aggregate hierarchy at microto submicron scales in an allophanic Andisol, Geoderma, 216, 62-74, https://doi.org/10.1016/j.geoderma.2013.10.005, 2014.

Asano, M., Tamura, K., Kawada, K., and Higashi, T.: Morphological and physico-chemical characteristics of soils in a steppe region of the Kherlen River basin, Mongolia, J. Hydrol., 333, 100108, https://doi.org/10.1016/j.jhydrol.2006.07.024, 2006.
Asano, M., Wagai, R., Yamaguchi, N., Takeichi, Y., Maeda, M., Suga, H., and Takahashi, Y.: In Search of a Binding Agent: Nano-Scale Evidence of Preferential Carbon Associations with Poorly-Crystalline Mineral Phases in Physically-Stable, Clay-Sized Aggregates, Soil Systems, 2, 32, https://doi.org/10.3390/soilsystems2020032, 2018.

Baisden, W. T., Amundson, R., Cook, A. C., and Brenner, D. L.: Turnover and storage of $\mathrm{C}$ and $\mathrm{N}$ in five density fractions from California annual grassland surface soils, Global Biogeochem. Cy., 16, 1117, https://doi.org/10.1029/2001GB001822, 2002.

Balesdent, J., Chenu, C., and Balabane, M.: Relationship of soil organic matter dynamics to physical protection and tillage, Soil Till. Res., 53, 215-230, https://doi.org/10.1016/S01671987(99)00107-5, 2000.

Barnhisel, R. and Bertsch, P.: Chlorites and hydroxy-interlayered vermiculite and smectite, in: Minerals in Soil Environments, 2nd Edn., edited by: Dixon, J. B. and Weed, S. B., Soil Science Society of America Book Series, Soil Science Society of America, Madison, WI, USA, 729-788, 1989.

Barré, P., Fernandez-Ugalde, O., Virto, I., Velde, B., and Chenu, C.: Impact of phyllosilicate mineralogy on organic carbon stabilization in soils: incomplete knowledge and exciting prospects, Geoderma, 235-236, 382-395, https://doi.org/10.1016/j.geoderma.2014.07.029, 2014.

Bascomb, C. L.: Distribution of pyrophosphate-extractable iron and organic carbon in soils of various groups, J. Soil Sci., 19, $251-$ 268, https://doi.org/10.1111/j.1365-2389.1968.tb01538.x, 1968.

Basile-Doelsch, I., Amundson, R., Stone, W. E. E., Borschneck, D., Bottero, J. Y., Moustier, S., Masin, F., and Colin, F.: Mineral control of carbon pools in a volcanic soil horizon, Geoderma, 137, 477-489, https://doi.org/10.1016/j.geoderma.2006.10.006, 2007.

Basile-Doelsch, I., Brun, T., Borschneck, D., Masion, A., Marol, C., and Balesdent, J.: Effect of landuse on organic matter stabilized in organomineral complexes: A study combining density fractionation, mineralogy and $\delta^{13} \mathrm{C}$, Geoderma, 151, 77-86, https://doi.org/10.1016/j.geoderma.2009.03.008, 2009.

Basile-Doelsch, I., Balesdent, J., and Rose, J.: Are interactions between organic compounds and nanoscale weathering minerals the key drivers of carbon storage in soils?, Environ. Sci. Technol. 49, 3997-3998, https://doi.org/10.1021/acs.est.5b00650, 2015.

Blankinship, J. C., Berhe, A. A., Crow, S. E., Druhan, J. L., Heckman, K. A., Keiluweit, M., Lawrence, C. R., Marín-Spiotta, E. Plante, A. F., Rasmussen, C., Schädel, C., Schimel, J. P., Sierra, C. A., Thompson, A., Wagai, R., and Wieder, W. R.: Improving understanding of soil organic matter dynamics by triangulating theories, measurements, and models, Biogeochemistry, 140, 113, https://doi.org/10.1007/s10533-018-0478-2, 2018.

Chen, C., Dynes, J. J., Wang, J., and Sparks, D. L.: Properties of Fe-Organic Matter Associations via Coprecipitation versus Adsorption, Environ. Sci. Technol. 48, 13751-13759, https://doi.org/10.1021/es503669u, 2014.

Chen, C., Hall, S. J., Coward, E., and Thompson, A.: Ironmediated organic matter decomposition in humid soils can counteract protection, Nat. Commun., 11, 2255, https://doi.org/10.1038/s41467-020-16071-5, 2020.

Christensen, B. T.: Physical fractionation of soil and structural and functional complexity in organic matter turnover, 
Eur. J. Soil Sci., 52, 345-353, https://doi.org/10.1046/j.13652389.2001.00417.x, 2001.

Churchman, G. J. and Tate, K. R.: Aggregation of clay in six New Zealand soil types as measured by disaggregation procedures, Geoderma, 37, 207-220, https://doi.org/10.1016/00167061(86)90049-2, 1986.

Coleman, K. and Jenkinson, D. S.: RothC-26.3 - A Model for the turnover of carbon in soil, in: Evaluation of Soil Organic Matter Models, edited by: Powlson, D. S., Smith, P., and Smith, J. U., Springer, Berlin, Heidelberg, 1996.

Cornell, R. M. and Schwertmann, U.: The Iron Oxides: Structure, Properties, Reactions, Occurences and Uses, 2nd Edn., WileyVCH, Weinheim, Germany 664 pp., 2003.

Coward, E. K., Thompson, A. T., and Plante, A. F.: Ironmediated mineralogical control of organic matter accumulation in tropical soils, Geoderma, 306, 206-216, https://doi.org/10.1016/j.geoderma.2017.07.026, 2017.

Coward, E. K., Thompson, A., and Plante, A. F.: Contrasting Fe speciation in two humid forest soils: Insight into organomineral associations in redox-active environments, Geochim. Cosmochim. Ac., 238, 68-84, https://doi.org/10.1016/j.gca.2018.07.007, 2018.

Crow, S., Reeves, M., Schubert, O., and Sierra, C.: Optimization of method to quantify soil organic matter dynamics and carbon sequestration potential in volcanic ash soils, Biogeochemistry, 123, 27-47, https://doi.org/10.1007/s10533-014-0051-6, 2014.

Dahlgren, R., Shoji, S., and Nanzyo, M.: Mineralogical characteristics of volcanic ash soils, in: Volcanic Ash Soils: genesis, properties, and utilization, edited by: Shoji, S., Nanzyo, M., and Dahlgren, R., Elsevier, Amsterdam, The Netherlands, 101-143, 1993.

Dai, Q.-X., Ae, N., Suzuki, T., Rajkumar, M., Fukunaga, S., and Fujitake, N.: Assessment of potentially reactive pools of aluminum in Andisols using a five-step sequential extraction procedure, Soil Sci. Plant Nutr., 57, 500-507, https://doi.org/10.1080/00380768.2011.598445, 2011.

Drees, R. L., Wilding, L., Smeck, N., and Senkayi, A.: Silica in soils: quartz and disordered silica polymorphs, in: Minerals in Soil Environments, 2nd Edn., edited by: Dixon, J. B. and Weed, S. B., Soil Science Society of America Book Series, Soil Science Society of America, Madison, WI, USA, 913-974, 1989.

Dultz, S., Woche, S. K., Mikutta, R., Schrapel, M., and Guggenberger, G.: Size and charge constraints in microaggregation: Model experiments with mineral particle size fractions, Appl. Clay Sci., 170, 29-40, https://doi.org/10.1016/j.clay.2019.01.002, 2019.

Eusterhues, K., Rumpel, C., Kleber, M., and Kögel-Knabner, I.: Stabilisation of soil organic matter by interactions with minerals as revealed by mineral dissolution and oxidative degradation, Org. Geochem., 34, 1591-1600, https://doi.org/10.1016/j.orggeochem.2003.08.007, 2003.

Ferris, F. G., Tazaki, K., and Fyfe, W. S.: Iron oxides in acid mine drainage environments and their association with bacteria, Chem. Geol., 74, 321-330, https://doi.org/10.1016/00092541(89)90041-7, 1989.

Filimonova, S., Kaufhold, S., Wagner, F. E., Häusler, W., and Kögel-Knabner, I.: The role of allophane nano-structure and $\mathrm{Fe}$ oxide speciation for hosting soil organic matter in an al- lophanic Andosol, Geochim. Cosmochim. Ac., 180, 284-302, https://doi.org/10.1016/j.gca.2016.02.033, 2016.

Fujii, K., Hayakawa, C., Inagaki, Y., and Ono, K.: Sorption reduces the biodegradation rates of multivalent organic acids in volcanic soils rich in short-range order minerals, Geoderma, 333, 188199, 2019.

Garcia Arredondo, M., Lawrence, C. R., Schulz, M. S., Tfaily, M. M., Kukkadapu, R., Jones, M. E., Boye, K., and Keiluweit, M.: Root-driven weathering impacts on mineral-organic associations in deep soils over pedogenic time scales, Geochim. Cosmochim. Ac., 263, 68-84, https://doi.org/10.1016/j.gca.2019.07.030, 2019.

Gunina, A. and Kuzyakov, Y.: Pathways of litter C by formation of aggregates and SOM density fractions: Implications from ${ }^{13} \mathrm{C}$ natural abundance, Soil Biol. Biochem., 71, 95-104, https://doi.org/10.1016/j.soilbio.2014.01.011, 2014.

Hatton, P.-J., Kleber, M., Zeller, B., Moni, C., Plante, A. F., Townsend, K., Gelhaye, L., Lajtha, K., and Derrien, D.: Transfer of litter-derived $\mathrm{N}$ to soil mineral-organic associations: Evidence from decadal ${ }^{15} \mathrm{~N}$ tracer experiments, Org. Geochem., 42, 14891501, https://doi.org/10.1016/j.orggeochem.2011.05.002, 2012.

Heckman, K., Grandy, A. S., Gao, X., Keiluweit, M., Wickings, K., Carpenter, K., Chorover, J., and Rasmussen, C.: Sorptive fractionation of organic matter and formation of organo-hydroxyaluminum complexes during litter biodegradation in the presence of gibbsite, Geochim. Cosmochim. Ac., 121, 667-683, https://doi.org/10.1016/j.gca.2013.07.043, 2013.

Heckman, K., Lawrence, C. R., and Harden, J. W.: A sequential selective dissolution method to quantify storage and stability of organic carbon associated with $\mathrm{Al}$ and $\mathrm{Fe}$ hydroxide phases, Geoderma, 312, 24-35, https://doi.org/10.1016/j.geoderma.2017.09.043, 2018.

Inagaki, T. M., Possinger, A. R., Grant, K. E., Schweizer, S. A., Mueller, C. W., Derry, L. A., Lehmann, J., and Kögel-Knabner, I.: Subsoil organo-mineral associations under contrasting climate conditions, Geochim. Cosmochim. Ac., 270, 244-263, https://doi.org/10.1016/j.gca.2019.11.030, 2020.

Jones, E. and Singh, B.: Organo-mineral interactions in contrasting soils under natural vegetation, Front. Environ. Sci., 2, https://doi:10.3389/fenvs.2014.00002, 2014.

Kaiser, K.: Sorption of natural organic matter fractions to goethite $(\alpha-\mathrm{FeOOH})$ : effect of chemical composition as revealed by liquid-state ${ }^{13} \mathrm{C}$ NMR and wet-chemical analysis, Org. Geochem., 34, 1569-1579, https://doi.org/10.1016/S01466380(03)00120-7, 2003.

Kaiser, K. and Guggenberger, G.: Mineral surfaces and soil organic matter, Eur. J. Soil Sci., 54, 219-236, https://doi.org/10.1046/j.1365-2389.2003.00544.x, 2003.

Kaiser, K. and Guggenberger, G.: Distribution of hydrous aluminium and iron over density fractions depends on organic matter load and ultrasonic dispersion, Geoderma, 140, 140-146, https://doi.org/10.1016/j.geoderma.2007.03.018, 2007.

Kaiser, K. and Zech, W.: Defects in Estimation of Aluminum in Humus Complexes of Podzolic Soils By Pyrophosphate Extraction, Soil Sci., 161, 452-458, 1996.

Keil, R. G. and Mayer, L. M.: 12.12 - Mineral Matrices and Organic Matter, in: Treatise on Geochemistry, 2nd Edn., edited by: Holland, H. D. and Turekian, K. K., Elsevier, Oxford, 337-359, 2014. 
Keiluweit, M., Bougoure, J. J., Nico, P. S., Pett-Ridge, J., Weber, P. K., and Kleber, M.: Mineral protection of soil carbon counteracted by root exudates, Nat. Clim. Change, 5, 588-595, https://doi.org/10.1038/nclimate2580, 2015.

Kitayama, K. and Aiba, S. I.: Ecosystem structure and productivity of tropical rain forests along altitudinal gradients with contrasting soil phosphorus pools on Mount Kinabalu,Borneo, J. Ecol., 90, 37-51, 2002.

Kleber, M., Eusterhues, K., Keiluweit, M., Mikutta, C., Mikutta, R., and Nico, P. S.: Mineral-Organic Associations: Formation, Properties, and Relevance in Soil Environments, in: Advances in Agronomy, edited by: Donald, L. S., Advances in Agronomy, Academic Press, Cambridge, MA, USA, 1-140, 2015.

Kramer, M. G. and Chadwick, O. A.: Climate-driven thresholds in reactive mineral retention of soil carbon at the global scale, Nat. Clim. Change, 8, 1104-1108, https://doi.org/10.1038/s41558018-0341-4, 2018.

Kramer, M. G., Sanderman, J., Chadwick, O. A., Chorover, J., and Vitousek, P. M.: Long-term carbon storage through retention of dissolved aromatic acids by reactive particles in soil, Glob. Change Biol., 18, 2594-2605, https://doi.org/10.1111/j.13652486.2012.02681.x, 2012.

Lalonde, K., Mucci, A., Ouellet, A., and Gelinas, Y.: Preservation of organic matter in sediments promoted by iron, Nature, 483, 198-200, https://doi.org/10.1038/nature10855, 2012.

Lavallee, J. M., Soong, J. L., and Cotrufo, M. F.: Conceptualizing soil organic matter into particulate and mineral-associated forms to address global change in the 21st century, Glob. Change Biol., 26, 261-273, https://doi.org/10.1111/gcb.14859, 2020.

Lawrence, C. R., Harden, J. W., Xu, X., Schulz, M. S., and Trumbore, S. E.: Long-term controls on soil organic carbon with depth and time: A case study from the Cowlitz River Chronosequence, WA USA, Geoderma, 247-248, 73-87, https://doi.org/10.1016/j.geoderma.2015.02.005, 2015.

Lehmann, J. and Kleber, M.: The contentious nature of soil organic matter, Nature, 528, 60-68, https://doi.org/10.1038/nature16069, 2015.

Lehmann, J., Kinyangi, J., and Solomon, D.: Organic matter stabilization in soil microaggregates: implications from spatial heterogeneity of organic carbon contents and carbon forms, Biogeochemistry, 85, 45-57, https://doi.org/10.1007/s10533-007-91053, 2007.

Loeppert, R. H. and Inskeep, W. P.: Iron, in: Methods of Soil Analysis, edited by: Sparks, D. L., Soil Sci. Soc. Am., Madison, WI, 639-664, 1996.

Lundström, U. S., van Breemen, N., and Bain, D.: The podzolization process. A review, Geoderma, 94, 91-107, https://doi.org/10.1016/S0016-7061(99)00036-1, 2000.

Masiello, C. A., Chadwick, O. A., Southon, J., Torn, M. S., and Harden, J. W.: Weathering controls on mechanisms of carbon storage in grassland soils, Global Biogeochem. Cy., 18, GB4023, https://doi.org/10.1029/2004gb002219, 2004.

Mayer, L. M. and Xing, B.: Organic Matter-Surface Area Relationships in Acid Soils, Soil Sci. Soci. Am. J., 65, 250-258, https://doi.org/10.2136/sssaj2001.651250x, 2001.

Mayer, L. M., Schick, L. L., Hardy, K. R., Wagai, R., and McCarthy, J.: Organic matter in small mesopores in sediments and soils, Geochim. Cosmochim. Ac., 68, 3863-3872, https://doi.org/10.1016/j.gca.2004.03.019, 2004.
Mikutta, R., Kleber, M., Torn, M. S., and Jahn, R.: Stabilization of Soil Organic Matter: Association with Minerals or Chemical Recalcitrance?, Biogeochemistry, 77, 25-56, 2006.

Mikutta, R., Zang, U., Chorover, J., Haumaier, L., and Kalbitz, K.: Stabilization of extracellular polymeric substances (Bacillus subtilis) by adsorption to and coprecipitation with Al forms, Geochim. Cosmochim. Ac., 75, 3135-3154, https://doi.org/10.1016/j.gca.2011.03.006, 2011.

Nierop, K. G. J. J., Jansen, B., and Verstraten, J. M.: Dissolved organic matter, aluminium and iron interactions: precipitation induced by metal/carbon ratio, $\mathrm{pH}$ and competition, Sci. Total Environ., 300, 201-211, https://doi.org/10.1016/S00489697(02)00254-1, 2002.

Oades, J. M. and Waters, A. G.: Aggregate Hierarchy in Soils, Aust. J. Soil Res., 29, 815-828, 1991.

Ohno, T., Heckman, K. A., Plante, A. F., Fernandez, I. J., and Parr, T. B.: ${ }^{14} \mathrm{C}$ mean residence time and its relationship with thermal stability and molecular composition of soil organic matter: A case study of deciduous and coniferous forest types, Geoderma, 308, 1-8, https://doi.org/10.1016/j.geoderma.2017.08.023, 2017.

Parfitt, R. L.: Allophane and imogolite: role in soil biogeochemical processes, Clay Miner., 44, 135-155, https://doi.org/10.1180/claymin.2009.044.1.135, 2009.

Parton, W. J., Schimel, D. S., Cole, C. V., and Ojima, D. S.: Analysis of Factors Controlling Soil Organic Matter Levels in Great Plains Grasslands, Soil Sci. Soc. Am. J., 51, 1173-1179, https://doi.org/10.2136/sssaj1987.03615995005100050015x, 1987.

Parfitt, R. and Childs, C.: Estimation of forms of $\mathrm{Fe}$ and $\mathrm{Al}-\mathrm{a}$ review, and analysis of contrasting soils by dissolution and Mossbauer methods, Soil Res., 26, 121-144, 1988.

Paustian, K., Ravindranath, N. H., and van Amstel, A. R.: 2006 IPCC Guidelines for National Greenhouse Gas Inventories, (Volume 4: Agriculture, Forestry and Other Land Use; No. Part 2), available at: https://www.ipcc-nggip.iges.or.jp/public/2006gl/ vol4.html (last access: 27 November 2020), 2016.

Percival, H. J., Parfitt, R. L., and Scott, N. A.: Factors Controlling Soil Carbon Levels in New Zealand Grasslands Is Clay Content Important?, Soil Sci. Soc. Am. J., 64, 1623-1630, https://doi.org/10.2136/sssaj2000.6451623x, 2000.

Porras, R. C., Hicks Pries, C. E., McFarlane, K. J., Hanson, P. J., and Torn, M. S.: Association with pedogenic iron and aluminum: effects on soil organic carbon storage and stability in four temperate forest soils, Biogeochemistry, 133, 333-345, https://doi.org/10.1007/s10533-017-0337-6, 2017.

Rasmussen, C., Heckman, K., Wieder, W. R., Keiluweit, M., Lawrence, C. R., Berhe, A. A., Blankinship, J. C., Crow, S. E., Druhan, J. L., Hicks Pries, C. E., Marin-Spiotta, E., Plante, A. F., Schädel, C., Schimel, J. P., Sierra, C. A., Thompson, A., and Wagai, R.: Beyond clay: towards an improved set of variables for predicting soil organic matter content, Biogeochemistry, 137, 297-306, https://doi.org/10.1007/s10533-018-0424-3, 2018.

Rennert, T.: Wet-chemical extractions to characterise pedogenic $\mathrm{Al}$ and Fe species - a critical review, Soil Res., 57, 1-16, https://doi.org/10.1071/SR18299, 2019.

Schneider, M. P. W., Scheel, T., Mikutta, R., van Hees, P., Kaiser, K., and Kalbitz, K.: Sorptive stabilization of organic matter by amorphous Al hydroxide, Geochim. Cosmochim. Ac., 74, 16061619, https://doi.org/10.1016/j.gca.2009.12.017, 2010. 
Schuppli, P. A., Ross, G. J., and McKeague, J. A.: The effective removal of suspended materials from pyrophosphate extracts of soils from tropical and temperate regions, Soil Sci. Soc. Am. J., 47, 1026-1032, https://doi.org/10.2136/sssaj1983.03615995004700050037x, 1983.

Shang, C. and Tiessen, H.: Organic matter stabilization in two semiarid tropical soils: Size, density, and magnetic separations, Soil Sci. Soc. Am. J., 62, 1247-1257, 1998.

Shoji, S., Nanzyo, M., and Dahlgren, R.: Volcanic Ash Soils: genesis, properties, and utilization, Developments in Soil Science: 21, Elsevier, Amsterdam, 288 pp., 1993.

Six, J., Merckx, R., Kimpe, K., Paustian, K., and Elliott, E. T.: A re-evaluation of the enriched labile soil organic matter fraction, Eur. J. Soil Sci., 51, 283-293, https://doi.org/10.1046/j.13652389.2000.00304.x, 2000.

Six, J., Conant, R. T., Paul, E. A., and Paustian, K.: Stabilization mechanisms of soil organic matter: Implications for C-saturation of soils, Plant Soil, 241, 155-176, https://doi.org/10.1023/A:1016125726789, 2002.

Smith, P.: Soil carbon sequestration and biochar as negative emission technologies, Glob. Change Biol., 22, 1315-1324, https://doi.org/10.1111/gcb.13178, 2016.

Sollins, P., Homann, P., and Caldwell, B. A.: Stabilization and destabilization of soil organic matter: mechanisms and controls, Geoderma, 74, 65-105, https://doi.org/10.1016/s00167061(96)00036-5, 1996.

Sollins, P., Glassman, C., Paul, E. A., Swanston, C., Lajtha, K., Heil, W., and Elliott, E. T.: Soil carbon and nitrogen: pools and fractions, in: Standard Soil Methods for Long-Term Ecological Research, edited by: Robertson, P., Coleman, D. C., Bledsoe, C. S., and Sollins, P., Oxford University Press, Oxford, 89-105, 1999.

Sollins, P., Kramer, M., Swanston, C., Lajtha, K., Filley, T., Aufdenkampe, A., Wagai, R., and Bowden, R.: Sequential density fractionation across soils of contrasting mineralogy: evidence for both microbial- and mineral-controlled soil organic matter stabilization, Biogeochemistry, 96, 209-231, https://doi.org/10.1007/s10533-009-9359-z, 2009.

Suda, A. and Makino, T.: Functional effects of manganese and iron oxides on the dynamics of trace elements in soils with a special focus on arsenic and cadmium: A review, Geoderma, 270, 68-75, https://doi.org/10.1016/j.geoderma.2015.12.017, 2016.

Swoboda-Colberg, N. G. and Drever, J. I.: Mineral dissolution rates in plot-scale field and laboratory experiments, Chem. Geol., 105, 51-69, https://doi.org/10.1016/0009-2541(93)90118-3, 1993.

Takahashi, T. and Dahlgren, R. A.: Nature, properties and function of aluminum-humus complexes in volcanic soils, Geoderma, 263, 110-121, https://doi.org/10.1016/j.geoderma.2015.08.032, 2016.

Tamrat, W. Z., Rose, J., Grauby, O., Doelsch, E., Levard, C., Chaurand, P., and Basile-Doelsch, I.: Soil organo-mineral associations formed by co-precipitation of $\mathrm{Fe}, \mathrm{Si}$ and $\mathrm{Al}$ in presence of organic ligands, Geochim. Cosmochim. Ac., 260, 15-28, https://doi.org/10.1016/j.gca.2019.05.043, 2019.

Tashiro, Y., Nakao, A., Wagai, R., Yanai, J., and Kosaki, T.: Inhibition of radiocesium adsorption on $2: 1$ clay minerals under acidic soil environment: Effect of organic matter vs. hydroxy aluminum polymer, Geoderma, 319, 52-60, https://doi.org/10.1016/j.geoderma.2017.12.039, 2018.
Tisdall, J. M. and Oades, J. M.: Organic-Matter and Water-Stable Aggregates in Soils, J. Soil Sci., 33, 141-163, 1982.

Torn, M. S., Trumbore, S. E., Chadwick, O. A., Vitousek, P. M., and Hendricks, D. M.: Mineral control of soil organic carbon storage and turnover, Nature, 389, 170-173, 1997.

Totsche, K. U., Amelung, W., Gerzabek, M. H., Guggenberger, G., Klumpp, E., Knief, C., Lehndorff, E., Mikutta, R., Peth, S., Prechtel, A., Ray, N., and Kögel-Knabner, I.: Microaggregates in soils, J. Plant Nutr. Soil Sc., 181, 104-136, https://doi.org/10.1002/jpln.201600451, 2018.

Turchenek, L. W. and Oades, J. M.: Fractionation of organo-mineral complexes by sedimentation and density techniques, Geoderma, 21, 311-343, 1979.

Urrutia, M. M. and Beveridge, T. J.: Formation of fine-grained metal and silicate precipitates on a bacterial surface (Bacillus subtilis), Chem. Geol., 116, 261-280, https://doi.org/10.1016/00092541(94)90018-3, 1994.

von Lützow, M., Kögel-Knabner, I., Ekschmitt, K., Flessa, H., Guggenberger, G., Matzner, E., and Marschner, B.: SOM fractionation methods: Relevance to functional pools and to stabilization mechanisms, Soil Biol. Biochem., 39, 2183-2207, https://doi.org/10.1016/j.soilbio.2007.03.007, 2007.

Wada, K.: Allophane and Imogolite, in: Minerals in Soil Environments, 2nd Edn., edited by: Dixon, J. B. and Weed, S. B., Soil Science Society of America Book Series, Soil Science Society of America, Madison, WI, USA, 1051-1087, 1989.

Wada, K. and Higashi, T.: The categories of aluminum- and ironhumus complexes in ando soils determined by selective dissolution, J. Soil Sci., 27, 357-368, https://doi.org/10.1111/j.13652389.1976.tb02007.x, 1976.

Wada, K. and Kakuto, Y.: Intergradient vermiculite-kaolin mineral in a Korean Ultisol, Clays Clay Miner., 31, 183-190, 1983.

Wagai, R. and Mayer, L. M.: Sorptive stabilization of organic matter in soils by hydrous iron oxides, Geochim. Cosmochim. Ac., 71, 25-35, https://doi.org/10.1016/j.gca.2006.08.047, 2007.

Wagai, R., Mayer, L. M., Kitayarna, K., and Knicker, H.: Climate and parent material controls on organic matter storage in surface soils: A three-pool, density-separation approach, Geoderma, 147, 23-33, https://doi.org/10.1016/j.geoderma.2008.07.010, 2008.

Wagai, R., Mayer, L. M., and Kitayama, K.: Extent and nature of organic coverage of soil mineral surfaces assessed by a gas sorption approach, Geoderma, 149, 152-160, https://doi.org/10.1016/j.geoderma.2008.11.032, 2009.

Wagai, R., Mayer, L. M., Kitayama, K., and Shirato, Y.: Association of organic matter with iron and aluminum across a range of soils determined via selective dissolution techniques coupled with dissolved nitrogen analysis, Biogeochemistry, 112, 95-109, https://doi.org/10.1007/s10533-011-9652-5, 2013.

Wagai, R., Kajiura, M., Asano, M., and Hiradate, S.: Nature of soil organo-mineral assemblage examined by sequential density fractionation with and without sonication: Is allophanic soil different?, Geoderma, 241-242, 295-305, https://doi.org/10.1016/j.geoderma.2014.11.028, 2015.

Wagai, R., Kajiura, M., Uchida, M., and Asano, M.: Distinctive roles of two aggregate binding agents in allophanic andisols: young carbon and poorly-crystalline metal phases with old carbon, Soil Systems, 2, 29, https://doi:10.3390/soilsystems2020029, 2018. 
Wan, J., Tyliszczak, T., and Tokunaga, T. K.: Organic carbon distribution, speciation, and elemental correlations within soil microaggregates: Applications of STXM and NEXAFS spectroscopy, Geochim. Cosmochim. Ac., 71, 5439-5449, https://doi.org/10.1016/j.gca.2007.07.030, 2007.

Wen, Y., Li, H., Xiao, J., Wang, C., Shen, Q., Ran, W., He, X., Zhou, Q., and Yu, G.: Insights into complexation of dissolved organic matter and $\mathrm{Al}(\mathrm{III})$ and nanominerals formation in soils under contrasting fertilizations using two-dimensional correlation spectroscopy and high resolution-transmission electron microscopy techniques, Chemosphere, 111, 441-449, https://doi.org/10.1016/j.chemosphere.2014.03.078, 2014.

Wieder, W. R., Grandy, A. S., Kallenbach, C. M., Taylor, P. G., and Bonan, G. B.: Representing life in the Earth system with soil microbial functional traits in the MIMICS model, Geosci. Model Dev., 8, 1789-1808, https://doi.org/10.5194/gmd-8-1789-2015, 2015.
Yang, J., Liu, J., Hu, Y., Rumpel, C., Bolan, N., and Sparks, D.: Molecular-level understanding of malic acid retention mechanisms in ternary kaolinite-Fe(III)-malic acid systems: The importance of Fe speciation, Chem. Geol., 464, 69-75, https://doi.org/10.1016/j.chemgeo.2017.02.018, 2017.

Yu, G.: Root Exudates and Microbial Communities Drive Mineral Dissolution and the Formation of Nano-size Minerals in Soils: Implications for Soil Carbon Storage, in: Root Biology, edited by: Giri, B., Prasad, R., and Varma, A., Springer International Publishing, Cham, 143-166, 2018.

Zhao, Q., Poulson, S. R., Obrist, D., Sumaila, S., Dynes, J. J., McBeth, J. M., and Yang, Y.: Iron-bound organic carbon in forest soils: quantification and characterization, Biogeosciences, 13, 4777-4788, https://doi.org/10.5194/bg-13-4777-2016, 2016. 